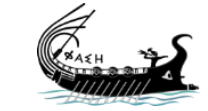

journal.phaselis.org
PHAS LLIS

Issue V (2019)
Disiplinlerarası Akdeniz Araştırmaları Dergisi

Journal of Interdisciplinary Mediterranean Studies

\author{
Issue V (2019)
}

\title{
Pedasa Athena Kutsal Alanı: Fenike Kökenli Kemik Oymalar ve Yakın Doğu Bağlantıları Üzerine Bazı Görüşler
}

The Sanctuary of Athena in Pedasa: Phoenician Bone Carvings and Some Remarks on the Near Eastern Contacts

\author{
Hülya BULUT \\ (D) https://orcid.org/0000-0001-5333-9145
}

open 2 access journals

The entire contents of this journal, Phaselis: Journal of Interdisciplinary Mediterranean Studies, is open to users and it is an 'open access' journal. Users are able to read the full texts, to download, to copy, print and distribute without obtaining the permission of the editor and author(s). However, all references to the articles published in the e-journal Phaselis are to indicate through reference the source of the citation from this journal.

Phaselis: Journal of Interdisciplinary Mediterranean Studies is a peer-reviewed journal and the articles which have had their peer reviewing process completed will be published on the web-site (journal.phaselis.org) in the year of the journal's issue (e.g. Issue IV: JanuaryDecember 2018). At the end of December 2018 the year's issue is completed and Issue V: January-December 2019 will begin.

Responsibility for the articles published in this journal remains with the authors.

Citation H. Bulut, "Pedasa Athena Kutsal Alanı: Fenike Kökenli Kemik Oymalar ve Yakın Doğu Bağlantıları Üzerine Bazı Görüşler”. Phaselis V (2019) 101-124. http://dx.doi.org/10.18367/Pha.19005

Received Date: 05.02.2019 | Acceptance Date: 22.02.2019

Online Publication Date: 26.03.2019

Editing Phaselis Research Project www.phaselis.org 


\title{
Pedasa Athena Kutsal Alanı: Fenike Kökenli Kemik Oymalar ve Yakın Doğu Bağlantıları Üzerine Bazı Görüşler
}

\author{
The Sanctuary of Athena in Pedasa: Phoenician Bone Carvings and Some Remarks on \\ the Near Eastern Contacts
}

\author{
Hülya BULUT*
}

\begin{abstract}
Öz: Bu çalışma, Bodrum Yarımadası'ndaki yerleşimlerden biri olan Pedasa'da Athena Kutsal Alanı'na adanan Hathor betimli kemik levha ve kadın başı gibi birkaç özel nitelikli sunu ve kentin Yakın Doğu bağlantıları üzerine bir değerlendirmenin ilk sonuçlarını kapsar. MÖ VII. yüzyıla tarihlenen ahşap mücevher kutusu kakması olan Hathor betimli kemik levha parçasının çok az sayıdaki örneği, Kamiros, Didyma Apollon Tapınağı ve Samos Heraion'dan bilinmektedir. Stilistik değerlendirmeler, Mısırlı bir tanrıça betimine sahip olmakla birlikte adı geçen merkezlerden gelen buluntuların Fenike kökenli bir atölyenin ürünleri olmaları gerektiğini ileri sürer. Bu prestij ürünleri, kente ticaret yoluyla ulaşmış olabileceği gibi Doğu Akdeniz'den ana vatanlarına dönen Karialılar tarafından, tanrıçaya şükran sunusu olarak da adanmış olabilir. Böylece antik kaynaklar ve arkeolojik verilerin daha önce ileri sürdüğü gibi MÖ VII. yüzyılda Yakın Doğu'da tüccar, paralı asker veya taş ustası olarak görev yapan Karialıların varlı̆ının yeni kanıtlarından söz edilebilir.
\end{abstract}

Anahtar sözcükler: Karia, Pedasa, Athena Kutsal Alanı, Hathor, Fenike Kemik Oymacılığı

Abstract: In the sanctuary of Athena in Pedasa, a Lelegian-Carian settlement located on the Bodrum peninsula, have recently been unearthed some prestigious artefacts, considered as indicators for international contacts of the local elites. This article presents first observations on the Near Eastern contacts according to diagnostic votive offerings, such as a bone plaque with an incised depiction of Hathor, and a female head. A limited number of similar examples of bone plaques pertained to Hathor and dated to the $\mathrm{VII} \mathrm{th}^{\text {th }}$ century B.C., were found in a grave in Camirus, as well as in the Apollo Sanctuary of Didyma, and in the Samian Heraion. They may have served as inlays of wooden boxes. Although the plaques demonstrate an Egyptian goddess, the stylistic evolution suggests, that all aforementioned examples must have been carved in a Phoenician workshop, which was most probably located in the east Mediterranean littoral. The bone plaque with Hathor depiction and the female figurine might have reached Pedasa via trade connections; alternatively, they might have been dedicated to Athena by the Carians to express their gratitude to the goddess and to celebrate their personal courage and success when they had returned safely to the homeland from the Eastern Mediterranean. Thus, they may present new evidence for the presence of the Carians in the Near East in the $\mathrm{VII}^{\text {th }}$ century BC, serving as mercenaries, merchants or stonemasons, as is already attested by the ancient literary sources and archaeological evidence.

Keywords: Caria, Pedasa, Athena Sanctuary, Hathor, Phoenician bone carving

* Dr. Öğr. Üyesi, Muğla Sıtkı Koçman Üniversitesi, Edebiyat Fakültesi, Arkeoloji Bölümü, Kötekli/Muğla hulyabulut@mu.edu.tr @ichttps://orcid.org/0000-0001-5333-9145 
Giriş

Leleg-Kar yerleşimi olan Pedasa'da sürüdürülen yeni araştırmalar, Tunç Çağı sonlarından itibaren yarımada halklarının kökeni, kendine özgü yerleşim organizasyonu ile yaşam kültürü, yakın çevre ve deniz aşırı uzak bağlantılarının anlaşıması için değerli katkılar sağlamaya devam etmektedir (Fig. 1) $)^{1}$. Bu çalışma, Pedasa Athena Kutsal Alanı'ndan gelen Hathor betimli kemik levha ve kadın başı gibi özel nitelikli birkaç sunu etrafında kentin Yakın Doğu bağlantıları üzerine bir değerlendirmenin ilk sonuçlarını içerir.

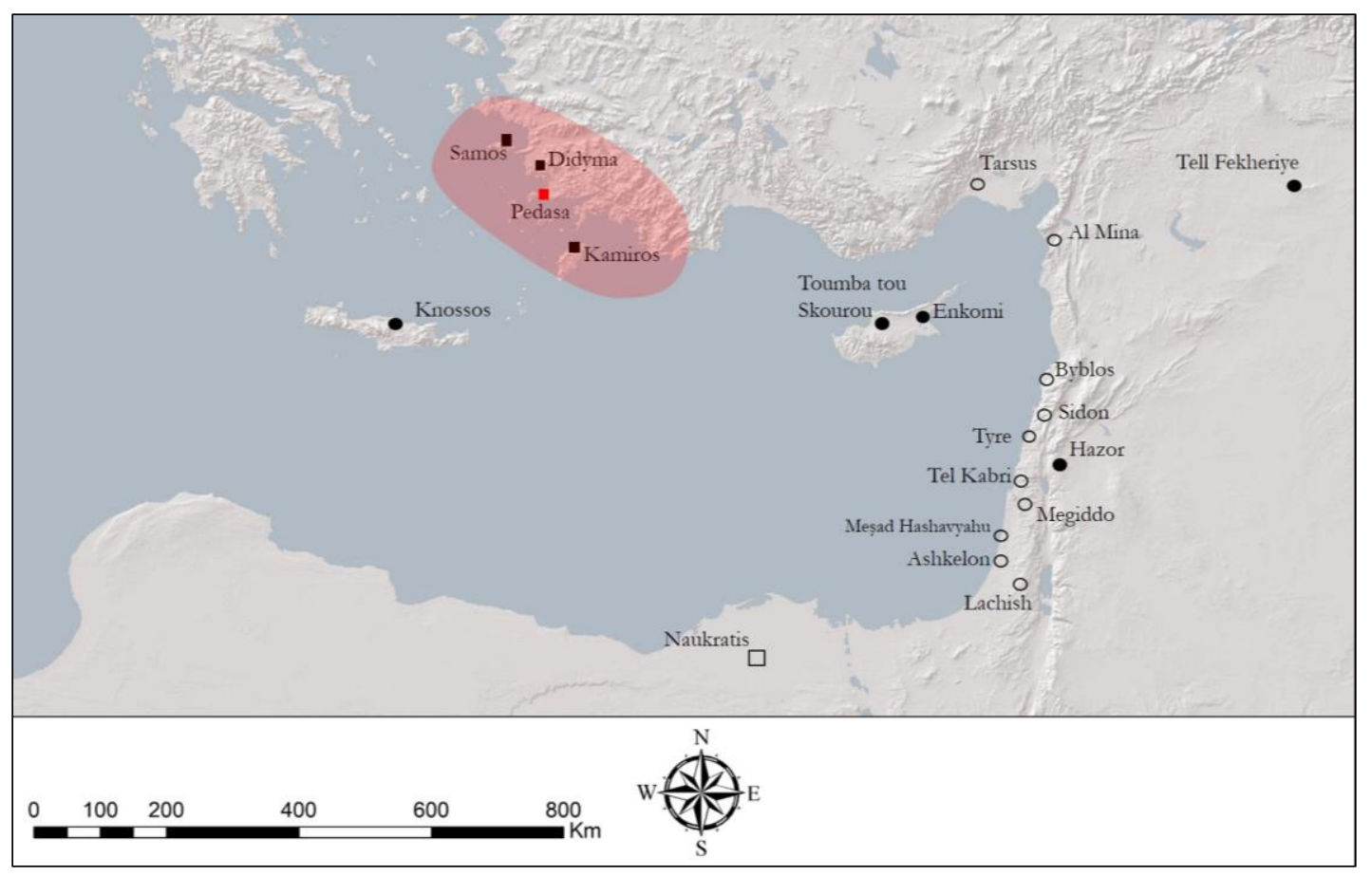

Fig. 1. Hathor betimli levhaların dağılımı ve makalede adı geçen başlıca merkezler

Athena Kutsal Alanı, doğuda akropolisi, batıda Termera territoryumu ve Kos Adası'nı gören bir tepenin eteklerinde kentin girişinde inşa edilmiştir. Bu haliyle, savunmaya elverişli doğal akropolis ${ }^{2}$ ile birlikte kentin merkezini oluşturur. Gerek topografik konumu gerekse Mausollos Dönemi'nde kent giriş çıkışlarını kontrol etmek üzere kutsal alanın eteklerinde inşa edilen Karakol Binası ${ }^{3}$, tapınağın "kentin koruyucusu" sıfatına vurgu yapar. Pedasa'daki Athena kültünün varlığı, öncelikle Herodotos'un ünlü pasajındaki bir imaya dayanır; O’na göre "Pedasalılar ve komşularının başına herhangi bir kötülük geleceği zaman Athena rahibesi uzun bir sakal çıkarıyordu ve bu sıra dışı durum o güne kadar üç defa gerçekleşmişti" (I. 175; VIII. 104)4. 19. yüzyıl gezginlerinin bölgedeki seyahatleri, antik yazarın ima ettiği Athena kültünün varlığıyla ilgili ilk epigrafik veriyi sunar ${ }^{5}$. Uzun bir aranın ardından 2007 yılında yeniden başlayan kazılar, kutsal alanın ve tanrıçanın epithetinin tanımlanması için ikna edici yeterince kanıt sağlamıştır. Tanrıçanın adı geçen yeni

1 Başlıca Diler 2009; Gümüş 2013; Bulut 2014a; Diler 2015, özellikle 157 - 158, 163 - 165; 2016; Özer - Özer 2017; Özer 2018a ve aşağıda dipnotlar 2-3, 7-13.

Diler - Adıgüzel 2015, 89 - 90; Baran 2017.

Özer - Türkoğlu 2009, 270 - 272; Çur 2014.

4 Herodotos (I. 175)'te bu olayın üç defa, VIII. 104'te ise iki defa gerçekleştiğini söyler. Strabon (XIII. 1. 59) da aynı bilgiyi Herodotos'tan alıntı yaparak aktarır.

5 Paton-Myres 1896, 216. 
yazıtlar ${ }^{6}$, göğsünde Gorgo betimi olan yelek şeklinde aegisi'ni kuşanan Athena heykeli ${ }^{7}$ ve kalkanlı pişmiş toprak Athena figürinlerinden ${ }^{8}$ oluşan yeni buluntular tapınağın varlığı ve yeri üzerindeki sisi ortadan kaldıran buluntulardan sadece birkaçıdır.

Mevcut verilere göre en erken Protogeometrik Dönem sonlarından itibaren işlev gören kutsal alan, ilki MÖ VI. yüzyıl ortalarından önce, ikincisi MÖ IV. yüzyııın ikinci yarısında inşa edilen iki teras üzerinde organize edilmiştir ${ }^{9}$. Buluntuların niteliğine ve farklı türdeki sunu ve eşyaların birbirleriyle sayısal oranlarına bakıldığında Doğu Ege'deki çağdaşı diğer kutsal alan konteksleriyle uyumlu olduğu görülür. Arkaik Dönem boyunca kutsal alanda düzenlenen kült törenlerinde kullanılan eşya veya sunular arasında ithal ve yerli seramikler ${ }^{10}$ ilk sırayı alırken onları sırasıyla pişmiş toprak figürinler ${ }^{11}$, yerli veya yabancı ziyaretçiler tarafından tanrıçaya sunulan, genellikle bulundukları kontekstlerin elit toplum üyeleriyle özdeşleştirilmesine kanıt gösterilen prestij eşyaları izler. Altın, bronz, fildişi, kemik veya fayanstan üretilen bu objeler, kült heykelinin giydirilmesi veya süslenmesi sırasında kullanılan takı ve elbise iğneleri ya da törenlerde kullanılan ritüel kapları veya nazarlıklardan oluşan kişisel sunular olarak kendini gösterir ${ }^{12}$. Pedasa'nın Mısır bağlantılarını destekleyen fayans ${ }^{13}$ sunuların yanı sıra (Fig. 2), çift diskli kemik fibula gibi (Fig. 3) bir çok kemik objenin benzerleri Ege dünyası ticari trafiğinin geçiş noktalarındaki Perakhora, Athena Lindia gibi uluslararası kutsal alanlarda ve Ephesos Artemision'da belgelenir ${ }^{14}$. Fildişi ve kemik objeler arasındaki baskın grubu iğneler, ahşap kutu süslemelerine ait çeşitli boyut ve formlardaki basit çizgisel bezemeli aplikler veya kült eşyalarının saplarına ait olabilecek parçalar oluştururken Hathor tasviri taşıyan kemik levha ve kadın başı, buluntular arasında ayrı bir yere sahiptir.

\section{Hathor Betimli Kemik Levha Parçası}

Mısır panteonunun güçlü tanrıçalarından biri olan Hathor'un betimi bulunan dikdörtgen kemik levha parçası, ahşap mücevher kutusunun kakması olmalıdır ${ }^{15}$ (Fig. 4a). Betim, Hathor başı üzerinde yükselen naos ön cephesi şeklindeki bir sistrumu ifade eder ${ }^{16}$. Tanrıçanın peruğu, alın ortasında ikiye ayrılarak omuzlara düşerken inek kulakları ikili kazıma şeritle stilize edilmiştir.

6 Yazıtlar Dr. Öğr. Üyesi Güray Ünver tarafından yayına hazırlanmaktadır.

7 Diler 2011, 329; Adıgüzel 2013, 15-16, 39-40, Lev. VIII.a-b, XIX. a-b.

8 Özer 2015a, 346, dipnot 5, Resim 4E.

9 Özer 2012, 172 - 175; 2016, 562-565; Bulut 2018a, 121, dipnot 2-3.

10 Özer 2009, 274; Diler 2011, 330; Bulut 2012, 172; Özer 2012, 173 -175, Resim 8; Bulut 2014b, 532, dipnot 58, Resim 3a-d; Özer 2015a, 346; 2015b, 343-344, 354, Resim 1-4; Bulut 2016, 560-562, dipnot 2, 6 - 8, Fig. 2a-d; Özer 2016, 564; 2017a; 2017b, 65-66, Resim 6B-C; Bulut 2018b, 88-89, Fig. 7-8; Özer 2018b.

11 Özer 2009, 274; Diler 2011, 330; Bulut 2014b, 532; Özer 2015a, 346, dipnot 5, Resim 4B-E; Diler - Kasar 2016, 262 - 269, 270 - 273, Fig. 1-5, 7 - 8;

12 Bulut 2016, 562, dipnot 9; Diler 2011, 330; Bulut 2013, 125-132.

13 Bulut 2018a.

14 Perakhora: Stubbings 1962, 436-437, PI. 185, no. A181-189; Lindos Athena: Blinkenberg 1931, 90-91, PI. 9 no. 133-134; Ephesos Artemision: Hogarth 1908, 187, PI. XXXII, no. 5; Muss 2008, 245, Kat. No: 140-141. Kökeni metal sarmal fibulalara dayandırılan çoğunlukla konsantrik daire grupları, sarmal veya rozet dizisinden oluşan bezemeye sahip bu tipin gelişimi ve örnekleri için Blinkenberg 1926, 262-271; Norton 1905, 353, no. 32-35, PI. CXL; Dawkins 1929, 224-225, PI. CXXII, no. 2, 4-11; Deonna 1938, PI. LXXXVI, no. $728-$ 730; Stubbings 1962, 433-435; Boardman 1966, 163, 165, PI. 104, no. 72-77; Boardman 1973, 80, 83, PI. 40, no. F151, 155; Varvarinou-Vai 2017, 194-195, Fig. 1-8; Kourayos-Burns 2017, 332, Fig. 10.

15 Env. no. PDS210714.KA.TT.M1.Y.4. Uzunluk : 0.41 m, Genişlik: 0.17 m, Kalınlık: 0.03 m.

16 Sistrum, Mısır'da sesheshet olarak adlandırılan, tanrıça onuruna düzenlenen törenlerde rahibeler veya kadın müzisyenler tarafından kullanılan rituel müzik aletine verilen Hellence isimdir. Sistrumlar, Hathor başının üzerinde yükselen ve çıngırakların yer aldığı biri kemerli diğeri naos formunda olmak üzere iki tiptedir (bakınız Anderson 1976, 40-63, Fig. 70-120; Friedman 1998, 215-216). 


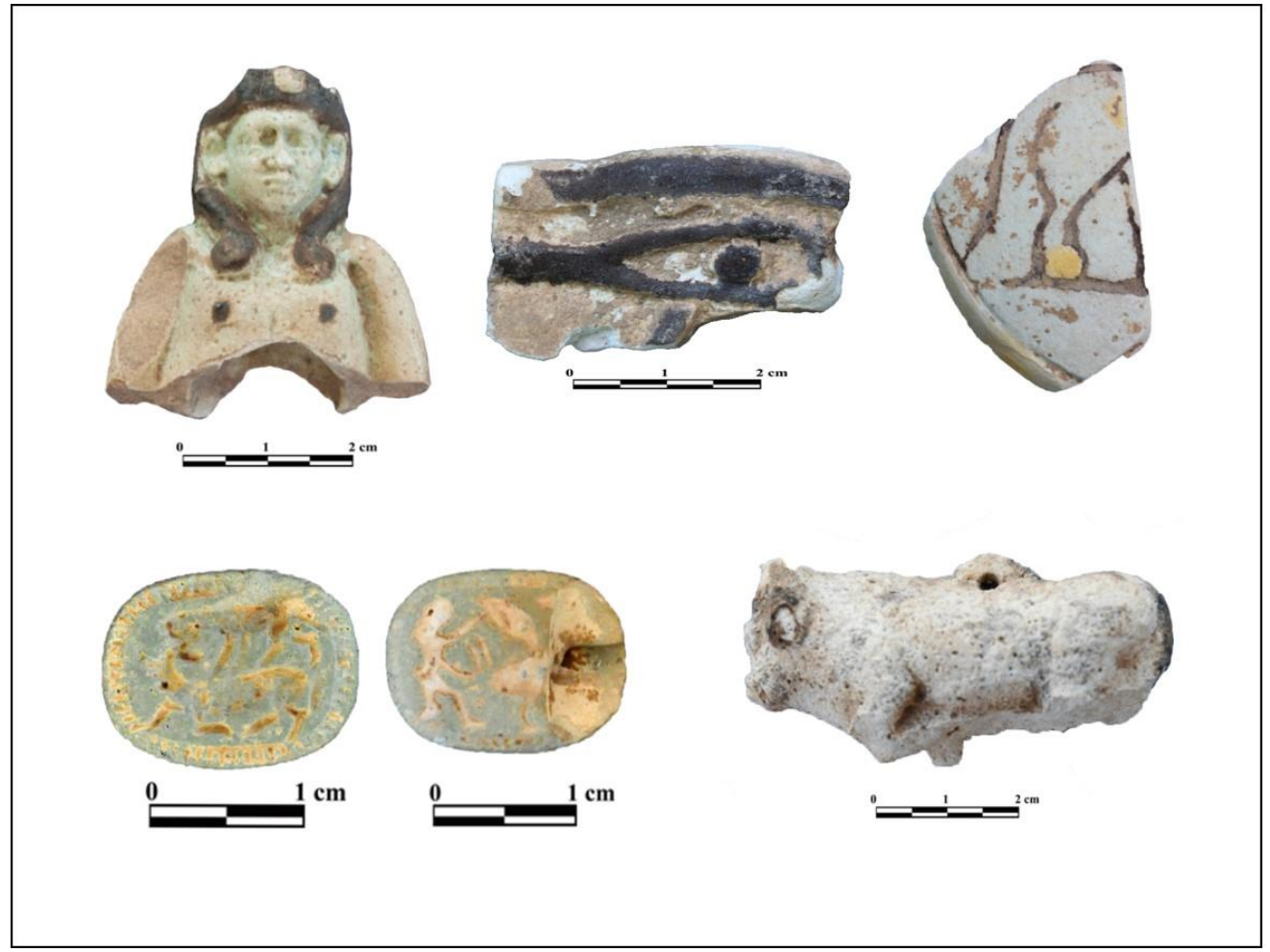

Fig. 2. Pedasa Athena Kutsal Alanı fayans buluntularından örnekler (Bulut 2018)

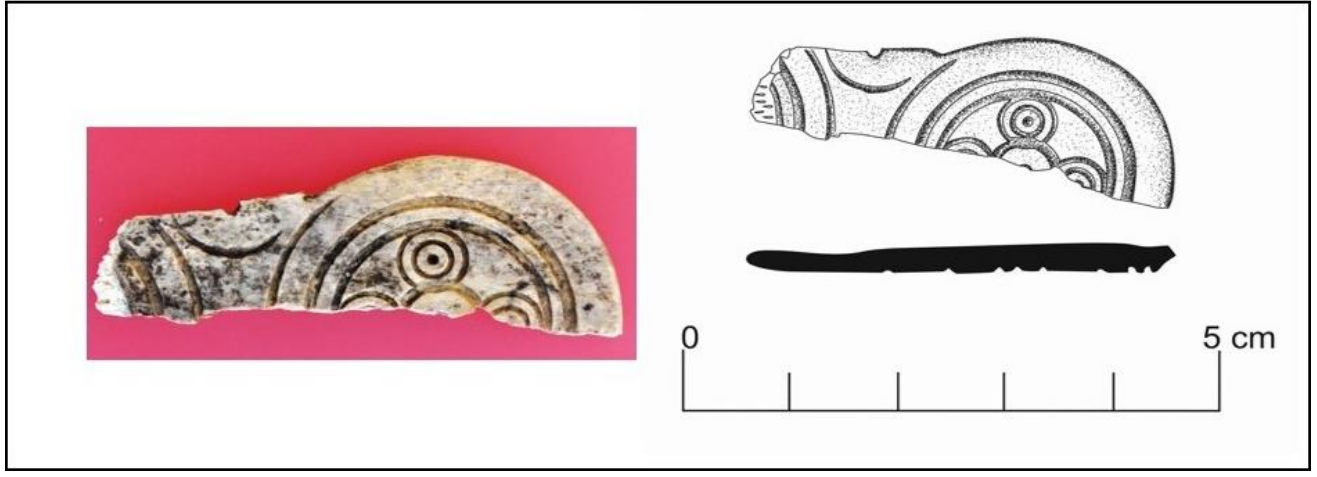

Fig. 3. Pedasa Athena Kutsal Alanı'nda ortaya çıkarılan çift diskli kemik fibula parçası (çizim: Meltem Aksakal)

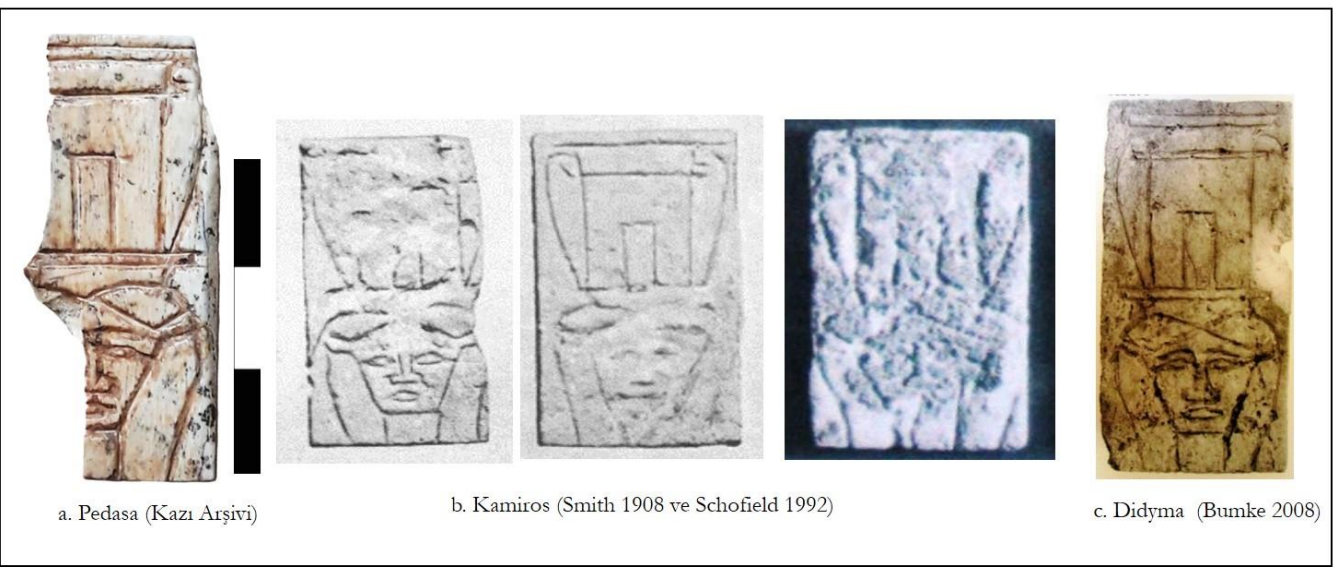

Fig. 4. Pedasa, Kamiros ve Didyma'dan yayınlanan Hathor betimli levhalar 
Yatay çizgiyle çekilen çene konturu aynı zamanda sistrum sapının bitişini gösterir. Mısır betimlerinde genellikle genç kadın yüzüne sahip olan tanrıçanın Pedasa levhasındaki yorumunda, geniş kanatlı trapezoidal burnu ve dudak çizimiyle sağlanan sert yüz ifadesi hakimdir. Enkomi ve Toumba tou Skourou'da bulunan levha parçaları, Hazor ve Kudüs Biblical Lands Museum'daki ahşap kutular ve Bethel'deki sistrumda görüldüğü gibi benzer yüz ifadeleri Bronz Çağ’a ait Kıbrıs ve Levant örnekleri arasında yaygındır ${ }^{17}$. Tanrıçanın başı ile yanlarda volütlerin eşlik ettiği naos ön cephesi arasında, tapınak temelini ifade eden ince bir silme yer alır. Yapı yüksekliğince uzanan bu volütlerin kökeni, Hathor'un boynuzlarına dayandırılmak istenir ${ }^{18}$. MÖ III. bin'den itibaren Ba'alat-Gebal (Astarte) ile eşleştirilerek tapınım gördüğü Byblos'tan gelen MÖ erken II. bin yıla ait, volüt şeklinde sonlandırılan boynuza sahip fildişi Hathor tasviri bu görüşü destekler niteliktedir ${ }^{19}$.

Hathor, Hellenistik Dönem öncesinde anavatanı Mısır dışında en yaygın kabul gören tanrıça olmasına karşın betimleri Hellen dünyasında oldukça azdır ${ }^{20}$. Fildişi, kemik veya fayanstan yapılan sınırlı sayıdaki örnek, Pedasa dışında, Kamiros, Samos, Didyma ve Knossos'tan gelir. 19. yüzyılın ortalarında Salzmann-Billiotti ${ }^{21}$ dönemi kazılarında Kamiros'taki mezarlardan birinde bulunan British Museum'daki fayans Yeni Yıl şişesinin ön yüzündeki tasvir, tanrıçanın levhalardaki ikonografisinin benzerini açıkça sergileyen örneklerden biridir ${ }^{22}$ (Fig. 5). Samos Heraion'da bulunan MÖ 640/630'a tarihlenen Mısır kökenli ünlü ayna sapı çift yönlü Hathor başından oluşur $^{23}$. Kamiros akropolis'inde yine Salzmann-Billiotti kazılarında ortaya çıkarılan kuyunun buluntuları arasında yer alan fildişi parçada ise tanrıçanın lüleleri ve levhanın yan kenarlarına yerleştirilen inek kulaklarından biri korunmuştur ${ }^{24}$. Ephesos Artemision'dan yayınlanan

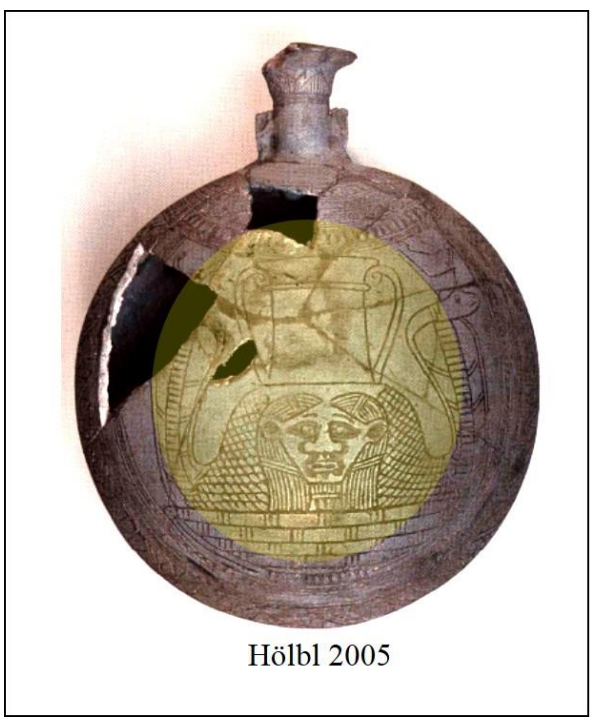

Fig. 5. Kamiros'ta bulunan fayans Yeni Yıl Şişesi (British Museum GRA 61.4-25.29) biri fildişi, diğeri kemikten iki levha üzerinde Astarte ile ilişkilendirilen kazıma kadın figürleri ellerinde Hathor başlı kemerli sistumlar taşır²5 (Fig. 6a-b). Fenike üretimi olarak tanımlanan ve

17 Ben -Tor 2009, 32-33, Fig. 28.

18 Anderson 1976, 40.

19 Hakimian 2008, 55-56, no. 26

20 ileride bahsedilecek olan fildişi, kemik ve fayanslar dışında Perakhora Hera Limenia kutsal alanı (Payne 1940, 142 - 143, PI. 46, no.1-2) ve Samos Heraion'dan bronz aynalar Hathor başlıklı naiskoslara sahiptir (Jantzen 1972, 31, $33-35$, Taf 33, no. B 432).

21 A. Salzmann ve A. Billiotti'nin 1859-1864 arasında Kamiros'ta yaptı̆̆ı kazılar hakkında Higgins 1954, 21-24; Webb 1978, 136-142; Schofield 1992, 173; Coulié 2014, 30- 34.

22 Mısır'a özgü bir rituel kabı olan matara şeklindeki şişenin diğer yüzünde ise tanrıçanın sembolü olan inek betimi bulunur (Lagarce- Leclant 1976, 237, dipnot 21; 243, dipnot 366, 368, PI. XXXI, no. 1-2 [British Museum GRA 61.4-25.29]; Hölbl 2005, 121, Abb. 16.). Ialysos Athena Tapınağı, Kamiros ve Pedasa Athena Kutsal Alanı'nda parça halinde korunan, tanrıçanın kutsal hayvanı inek betiminin olduğu birkaç örnek için bakınız Maiuri 1928, 77, Fig. 59 (Ialysos); Jacopi 1932/1933, 329, no. 2, renkli levha XIII (Kamiros); Bulut 2018a, 128, 137, no. 9, Fig. 2 (Pedasa).

23 Freyer-Schauenburg 1966, 12, 14, 112, 117, Taf. 33 (E.73); Niemeier 2016, 240.

24 Smith 1908, 179, PI. 30, no. 18; Schofield 1992, 176, PI. 3d (GR 1864.10-7.635).

25 Fildişi ve kemik levhalar ve ilgili kaynakça için bakınız Bammer 1985, 103-107, PI. XIV; Bammer 1992, 186, 190, no. 18-19, 204, PI. 9. c-d; Muss 2008, 243, no. 134 (Selçuk Efes Müzesi Env. no. 102/41/86) ve Muss 
MÖ VII. yüzyıla tarihlenen Mısır etkili Ephesos levhalarının kalın ve tutuk çizim karakteri, Pedasa, Didyma ve Kamiros'takilerin çizgi karakterleriyle çok yakın benzerdir.

Pedasa levhasının boyut, işlev ve stil açııından çok yakın paralelleri Kamiros ve Didyma Apollon Kutsal Alanı'ndan yayınlanmıştır (Fig. 4b-c). Samos Heraion'da altar çevresindeki yeni kazılarda ortaya çıkarılan ve mevcut örneklerle aynı özelliklere sahip henüz yayınlanmamıs bir levha daha bulunur ${ }^{26}$. Kamiros akropolis'inin güneyinde yer alan Papatislures Mevkii'ndeki (veya Papa ailoūres) mezarlardan birinden, neredeyse hepsi aynı ölçüde, üzerinde kazıma Hathor betimi bulunan üç adet kemik levha ortaya çıkarılmıştır (Fig. 4b) ${ }^{27}$. Buluntu durumları levhaların ahşap kutu süslemeleri olabileceğini düşündürür. Didyma Apollon Kutsal Alanı'nda Taxiarchis Tepesi'ndeki kazılardan gelen levha ise, hem Pedasa hem de Papatislures örnekleriyle benzer olmakla birlikte, bir fark dikkati çeker (Fig. 4c) ${ }^{28}$. Taxiarchis levhasında, naiskosun merkezinde yer alan figür diğerlerinde yoktur; şahlanan yılan başı şeklindeki bu figür, Hathor'un bir diğer sembolü olan Uraeus'u ifade eder ${ }^{29}$. Uraeus'un varlı-
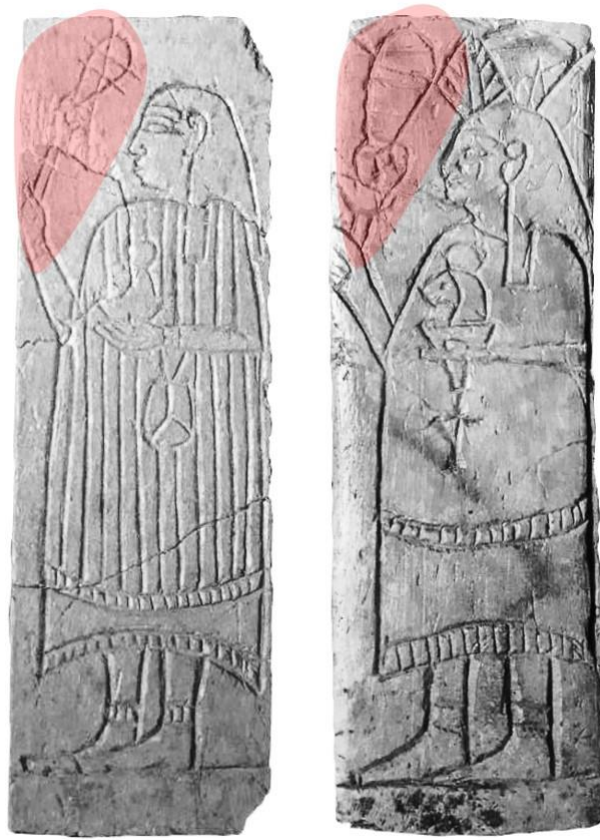

Ephesos Artemision (Muss 2008)

Fig. 6. Ephesos Artemision'dan gelen kemik ve fildişi levhalar ğı, Taxiarchis levhasının gerçek bir Hathor sistrumundan örnek alınarak çizildiğini gösteren detaylardan biridir. Yaklaşık olarak aynı tarihte Saite Dönemi'nin (MÖ 664-525) fayans sistrumları, esinlenmenin kaynağı olan örneklerin benzerlerini sunar ${ }^{30}$.

Kamiros, Didyma ve Pedasa'dakilerden oldukça farklı olmakla birlikte, Ege dünyasından bili-

2008, 242, no. 133 (Selçuk Efes Müzesi Env. no. 19/27/84). Artemision'da bulunan bir diğer fildişi levha parçasında ise boynunda lotus çiçeği asılı halde tanrıçanın kutsal hayvanı inek betimlenmiştir (Hogarth 1908, 195, Lev. XL, no. 22 (İstanbul Arkeoloji Müzesi Env. no. 2767); Muss 2008, 243, no. 135. Fenike işi levhalar dışında, Kroisos Tapınağı batısında ve altar çevresindeki kazılarda Hellen dünyasında çok nadir görülen Batı Semitik-Fenike kült geleneğinde eşek kurban edildiğine dair kanıtlar ortaya çıkarılmıştır (Bammer 1985, 106-107). Bammer ve Hölbl, Artemision'dan gelen örneklerle Ephesos'a yabancı bu sıradışı hayvan kurban geleneğine dayanarak MÖ VIII. -VII. yüzyılda Ege dünyasının başka yerlerinden olduğu gibi Ephesos'ta yerleşik Fenikelilerin olabileceğini ileri sürer (Hölbl 1993, 250, Taf. XXII. 1-2).

26 Levhanın bilgisini paylaşan ve burada bahsedilmesine onay veren Prof. Dr. Wolf - Dietrich Niemeier ve Dr. Jan-Marc Henke'ye teşekkür ederim (DAI Atina Şubesi, 15 Ocak 2019 tarihli görüşme).

27 Smith 1908, 180, pl. 30, no.4 ve 6. (Boyutları: no. 4: $0.37 \times 0.17$ m; no. 6: $0.37 \times 0.2$ m); Schofield 1992, 176, Pl. 3e (Mezar P7. GR 1864.10-7.694-696).

28 Bumke 2008, 92, Abb.9 (Taxiarchis - Grabung, Env. no. MM 01-256. Boyutları: 0. $39 \times 0.19 \times 0.03$ m).

29 Uraeus (Uraios) Mısır'da tanrı ve kraliyet sembollerinden biridir ve şahlanan kobra yılanı şeklinde diadem veya taçlarda gösterilir (Lexicon der Ägyptologie VI (1986) 864-868, s.v. Uräus (K. Martin); Lurker 1994, 125). Uraeus bulunan Hathor sistrumları için Anderson 1976, 53-56, Fig. 94- 102; Friedman 1998, 102, 215-216, no. 91, Fig. 49. Naukratis'teki Hathor tasvirli fayans levha için Gardner 1888, 87, PI. XIX, no. 15. Kıbrıs Hathor başlıklarındaki Uraeus'lar için bakınız Hermary 1985, 657-699, Fig. 1-16, 20-21,2 9-30, 39.

30 Anderson 1976,53-56, fig. 94-101; Schofield 1992, 176, 184, PI. 3f; Friedman 1998, 215-216, no. 91, Fig. 49. 
nen bir diğer Hathor betimli levha parçası da Knossos'tan yayınlanmıştır (Fig. 7a) ${ }^{31}$. Knossos'a Arkaik Dönem'de geldiği varsayılan levhanın, Mısır ve onun etkisiyle MÖ XVII. yüzyılın sonlarından itibaren Filistin-Suriye Bölgesi ve Kıbrıs'ta üretilen Bronz Çağ örnekleriyle olan yakın benzerliği göze çarpar ${ }^{32}$. Knossos levhası, Yakın Doğu benzerleri gibi daha erken bir tarihe, en azından Geç Bronz Çağ'a ait gibi gözükmektedir. Ege - Akdeniz deniz ticaret rotası üzerinde kilit noktada yer alan Kıbrıs'ın kuzeybatısında, Morphou yakınındaki Toumba tou Skourou ${ }^{33}$ (Fig. 7b) ve yine adanın doğu kıyısında Enkomi'den ${ }^{34}$ (Fig. 7c) yayınlanan, Knossos levhası ile benzer Hathor betimlerine sahip MÖ XVI. yüzyıla ait kemik ve fildişi levha parçaları; Hazor'daki tören sarayının MÖ XIII. yüzyıla tarihlenen tahrip depozitinde ortaya çıkarılmasına karşın stilistik açıdan MÖ XVI.-XV. yüzyıla verilen ahşap mücevher kutularına ait kemik levhalar, geleneğin Bronz Çağ’a kadar geri gittiğini kanıtlar (Fig. 8)

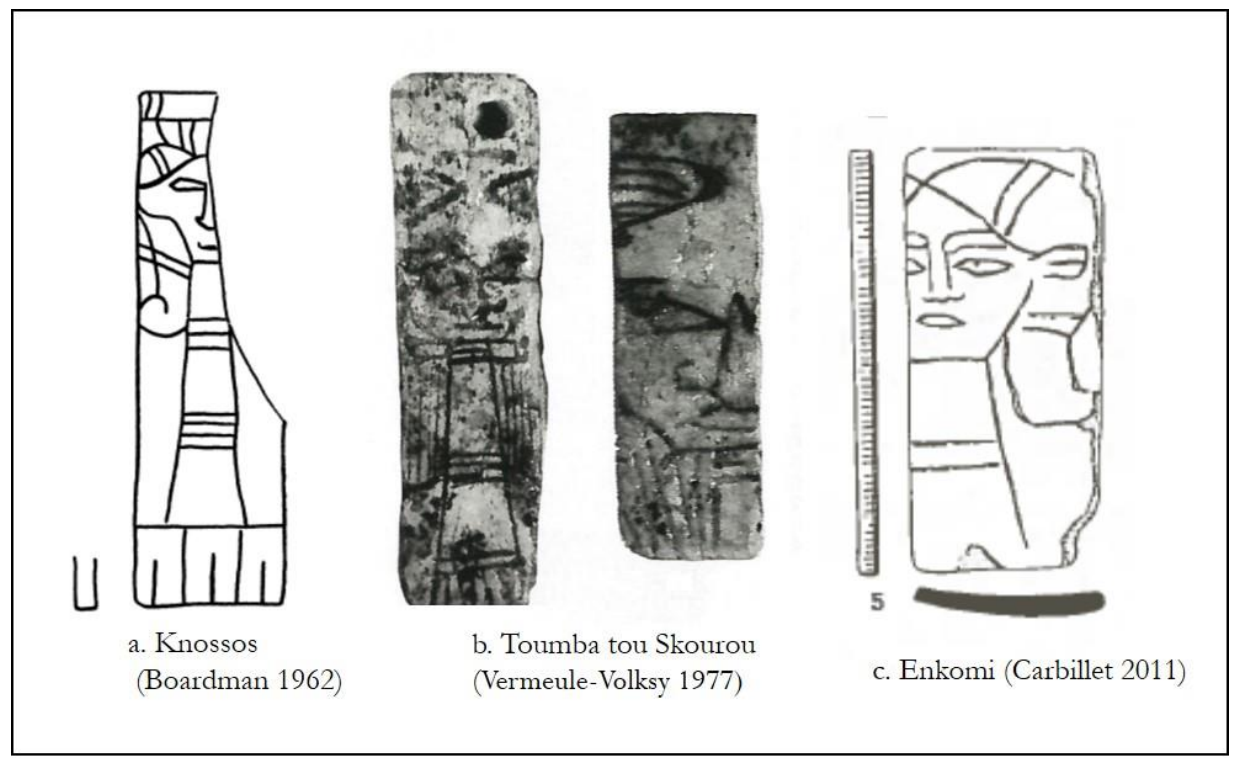

Fig. 7. Knossos, Toumba tou Skourou ve Enkomi levhaları

Kamiros, Didyma ve Pedasa levhalarını Bronz Çağ'daki ahşap kaplama geleneğinin Arkaik Dönem'deki devamı olarak yorumlamak yanlış olmayacaktır. Bronz Çağ öncülleri mezar ve yerleşimden gelirken Kamiros dışında Doğu Ege'deki az sayıdaki örnek kutsal alanlarda ortaya

31 Boardman 1962, 30-31, Fig. 2.

32 El Lahun'da 12. Hanedan Dönemi'ne ait prenses Sit-Hat-hor-Yūnet'e ait kutunun kapağını süsleyen, gözleri beyaz ve siyah taşla, kaşları mavi fayansla renklendirilen altın Hathor başları için bakınız Winlock 1934, 1314, fig. 3. Mısır kökenli ve tanrıça Hathor'un geleneksel saç tasarımı olan ve onun adıyla literatüre geçen saç tipi, Orta Bronz Çağ'dan itibaren Yakındoğu ve Anadolu'da sadece yerel tanrıçalarda değil aynı zamanda fantastik yaratıkların saç kostümleri arasında görülür (Loud 1939, 18, PI. 44, no. 190-193; Kantor 1958, 59-60, 67, PI. 61, no. 48-49 [Tell Fekheriye]; PI. 68.B [Megiddo]- C [Ras Şamra]; Barnett 1975, PI. VIII, C55; PI. XXI, S6, S18; PI. XIX, S13; PI. XXVI, S20; Vermeule- Wolsky 1977, 84; Ben-Tor 2009, 31, 34, 40, Fig. 27,30, 37; Margueron 2008, 238, Fig. 80; Cluzan 2008, 348-349, no. 214-215). Kenaan Bölgesi'ndeki kutu veya oyun tahtaları için bakınız Ben-Tor 2009, 59-60.

33 Toumba tou Skourou Mezar 1'de, 1 ve 3 no.lu odadan gelen MÖ XVI. yüzyıl üçüncü çeyreğine tarihlenen ve olasılıkla oyun tahtasının süslemelerine ait, Mısır etkileri altında yerel gelenekte bezeli kemik levhalar için bakınız Vermeule- Wolsky 1977, 80-84, 88, Fig. 1, PI. XVIII, B1. 6A-B, B1.8A, B1. 10A-B; Carbillet 2011, 38-39, 302-303, no. G2-G5, PI. 24.

34 Enkomi Mezar 629'dan gelen MÖ XVI. yüzyıla tarihlenen levha için Courtois 1984, 58, 62, no. 556, Fig. 18. 9; Courtois- Lagarce 1986, 130, PI. XXV, no. 5 (Chypriote Récent I); Carbillet 2011, 37-39, 302, no. G1, PI. 24.

35 Ben-Tor 2009, 8-10, Fig. 3-5; 16, Fig. 10 (Box I ve II); 19, Fig. 12. B1a-e. 
çıkarılmıştır. Buluntu durumu ahşap kalıntılara dair bir bilgi vermese de Kamiros üçlüsü mezar buluntusu olarak bireyin kişisel eşyaları arasındadır. Mezar sahibinin Doğu Akdeniz'e giden bir Kamiroslu mu yoksa adaya yerleşen göçmen bir yerleşimci mi olduğunun cevabını vermek güçtür. Kutsal alanlardan gelen Hathor tasvirli sunular ise cevaplanması gereken birkaç soru açığa çıkarır; Mııır kökenli bir tanrıça betiminin Pedasa'da Athena, Didyma'da Apollon ve Samos'ta Hera ile özdeşleştiriliyor muydu ve bu eşyalar kimler tarafından sunulmuştu? Bilindiği gibi Hathor, Mısır panteonunun diğer tanrılarına nazaran yabancı topraklarda daha erken dönemden itibaren kabul görmüş ve yerel tanrıçalarla özdeşleştirilmiştir ${ }^{36}$. Örneğin, tanrıça Mısır ile bağlantılı merkezlerden biri olan Byblos'ta MÖ III. binden itibaren tapınım görürken ikonografisi kentin Semitik ana tanrıçası Ba'alat Gebal ile ilişkilendirilir. Tanrıçanın Suriye Fenike kıyılarında MÖ II. binde giderek artan tapınımı hem bölgede hem de Kıbrıs'ta MÖ I. binde yaygınlaşır ${ }^{37}$. Fenike'de olduğu gibi Hathor, Kıbrıs'ta da yerel bir tanrıçayla, Astarte ile özdeşleştirilirr ${ }^{38}$. MÖ VIII. yüzyıl sonlarına ait erken örnekleri olmakla birlikte tanrıçanın ikonografisi özellikle MÖ VI. yüzyılın ortalarından itibaren adada popülerdir ${ }^{39}$. Amathus, Kition, Paphos, Vouni ve Tamassos'tan gelen çok sayıda Hathor sistrumlu taş başlık bunu kanıtlar ${ }^{40}$. Tell Fekheriye'den gelen Hathor betimli iki fildişi parça, MÖ XIII. yüzyılda tanrıçanın ikonografisinin kıyıdan çok içeriye, Yukarı Mezopotamya'ya kadar nüfuz ettiğini gösterir ${ }^{41}$.

Mısır kökenli bir tanrıçaya ait, belki de dekoratif bezeme özelliğinden dolayı tercih edilen kutunun kaplaması olan Pedasa levhası, Hathor'un, Yakın Doğu ve Kıbrıs'ta olduğu gibi, Pedasa'da Athena ile ilişkilendirildiği sonucunu çıkarmak için tek başına yeterli değildir. Fakat Knossos levhası da dahil olmak üzere Kıbrıs ve Levant'taki Bronz Çağ Hathor yorumlarında öne çıkan bir detay dikkatimizi bir kere daha Herodotos'un pasajına çeker (I. 175; VIII. 104). Knossos, Enkomi, Toumba tou Skourou ve Hazor betimlerinde görülen, yatay çizgilerle stilize edilen dikme üzerinde yükselen Hathor başlarının dikme ile kıyaslandığında bilinçli olarak büyük boyutlu gösterilmesi, onların törenlerde kullanılan taşınabilir tanrı betimi veya maskeleri olabileceklerini düşündürür ${ }^{42}$.

36 Lexicon der Ägyptologie II (1977), 1024- 1033, s.v. Hathor (F. Daumas); Lexicon Iconographicum Mythologiae Classicae IV.I (1988), 451-458, s.v. Hathor (G. Clerc); Bleeker 1973, 72-73. Hellen dünyasında Baaltis veya Atargatis olarak bilinen tanrıça Ba'alat Gebal genellikle Astarte ile özdeşleştirilir. Hathor ve aynı şekilde gemi ve gemiciliğin koruyucusu olan Ba'alat Gebal arasındaki ilişki Levant ve Mısır arasındaki ticari bağlantılara işaret eder. Mısırlı tüccarlara seyahatleri boyunca eşlik eden tanrıça aynı zamanda Mısır'da uzun bir üretim geçmişine sahip fayansın da koruyucu tanrıçasıydı.

37 Hermary 1985, 657-699; Schofield 1992, 176.

38 Schofield 1992, 176-177.

39 MÖ VIII. yüzyıl sonuna tarihlenen bronz kazanın kulp altında, kanatlı güneş kursuyla birlikte Yakın Doğu ikonografisinde tasvir edilen aplik Hathor betimi için bakınız Karageorghis 1973, 27-28, 108-114, Fig. 25, 28 (Mezar 79), PI. CCXLIII-CCXLIV, CCXLVI.

40 Hermary 1985, 657-699; Hermary 2000, 144-149, PI. 83-87, no. 969-972. Ancak betimleri Mısır örneklerinden biraz farklıdır; Kıbrıs'taki Hathor başlıklarında naiskos doğrudan peruğun üzerinden yükselirken Mısırlı örneklerde arada bir plinthos yer alır. Mısır ve etkisi altındaki Levant örneklerinde tanrıça inek kulağıyla betimlenirken Kıbrıs'taki yorumlarında insan kulağına sahiptir. Çeşitli formlarda tasvir edilen Hathor'un betimlemelerinden biri inek-tanrıça olduğu için Mısırlı örneklerde kadın yüzüne inek kulakları eklenir (bkz. Bleeker 1973, 22, 30-34, 80, Fig. 1; Friedman 1988, 215).

41 Kantor 1958, 59, 67, PI. 61, no. 48-49. Kantor, Tell Fekheriye'deki örnekleri, Fenike fildişlerinin öncülleri olarak değerlendirilen Mııır ve Asyatik etkiler altında şekillenen Kenaan fildişi ekolünün ürünleri arasına yerleştirir (aynı eser sayfa 64).

42 Dikme olarak yorumlanan başın oturduğu bölüm bir bakıma sistrum sapını da ifade ediyor olabilir (Ben Tor 2009, 33, Fig. 28). 


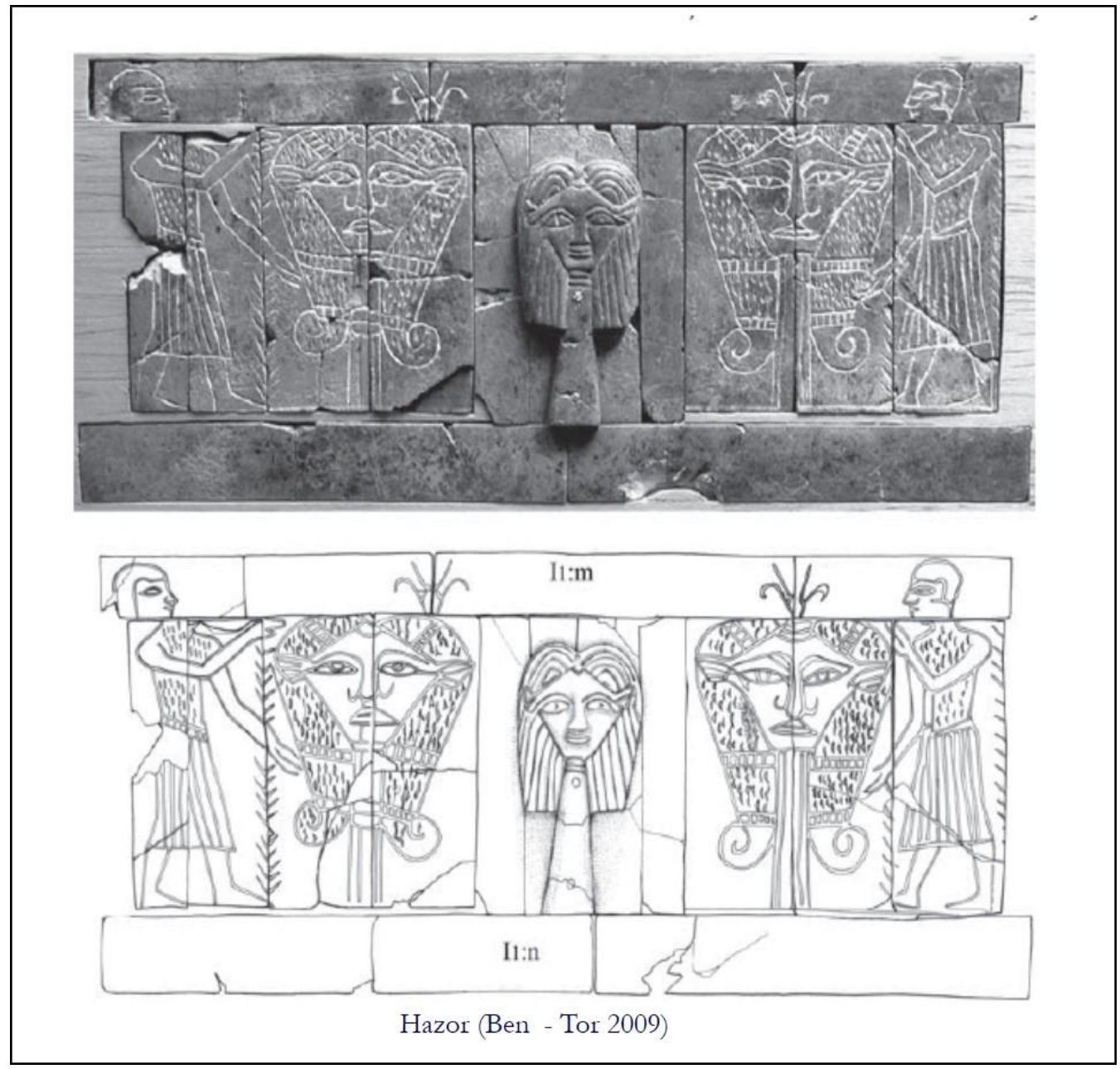

Fig. 8. Hazor'da bulunan ahşap mücevher kutusuna ait Hathor betimleri

Toumba tou Skourou ve Knossos'takilerde özellikle tanrıçanın sert ve erkeksi yüz ifadesi ve üzerinde yükseldiği dikme (veya sistrum sapı) dikkate alındığında, tasvir bütününde "sakalıı bir figür" gibi algılanabilir (Fig. 7). Vermeule - Wolsky de, Toumba tou Skourou levhalarındaki Hathor tasvirleriyle Mısır'da El Lahun'daki prenses Si-Hat-hor-Yūnet'in mezarından gelen kutudaki çizimlerde görülen ve "sakallı Hathor" olarak yorumlananlar arasında bir bağlantı kurar $^{43}$. Ek olarak, Ugarit'teki ${ }^{44}$ fildişi panelde görülen tanrıça Anat, Megiddo'daki ${ }^{45}$ Hitit kökenli fildişi levhadaki boynuzlu, Hathor tarzı peruklu ve sakallı figürler ile Miletos'tan ${ }^{46}$ gelen MÖ erken VII. yüzyıl pinaksları üzerinde kanatlı tanrıça olarak yorumlanan, çene altında sakal benzeri uzantıya sahip figürler bir taraftan girift Yakın Doğu ile Hellen plastik sanatları arasındaki esinlenmenin boyutunu gösterirken diğer taraftan Mısır - Yakın Doğu kökenli bir

43 Vermeule-Wolsky 1977, 84, dipnot 5.

44 Margueron 2008, 238, Fig. 80. Ugarit’teki kraliyet sarayından gelen Geç Bronz Çağ’a ait karyola paneli Suriye stiliyle birlikte belirgin bir şekilde Mısır zevkini de yansıtır. Paneldeki Hathor tarzı lüleli, kanatlı, boynuzlu ve boynuzları arasında astral disk bulunan tanrıça Anat, II. Ramses Dönemi'nde Mısır panteonuna girer ve Hathor'un karakteristik özelliklerini üstlenir (Schaeffer 1954, 54 - 55, PI. VIII; Ward 1969, 229, 236, Fig. 3). Dolayısıyla fildişi paneldeki tasvir, Mısırlı Hathor ile özdeşleşen Mezopotamya uyarlamasını yansıtır.

45 Loud 1939, 10, 14, no. 44, PI. 10 - 11; Alexander 1991, 162 - 163, Fig. 2 (Figürler boğa adamlar olarak yorumlanmıştır).

46 von Graeve 2007, 654-56, Abb. 2, Taf. 85. 1-2. 
tanrıçanın erken dönem lonia dini simgelerinin oluşumundaki etkisini ortaya koyar.

Herodotos'un uzak coğrafyalardaki olaylarla ilgili detaylı bilgileri düşünüldüğünde, çok yakın komşusundaki tapınak hakkında bu denli az bilgi vermesi ve rahibenin sakalının uzamasına neden olan kötü olayların içeriğinden bahsetmemesi şaşırtıııdır (I. 175; VIII. 104). Antik yazarın pasajı dışında herhangi bir verinin olmayışı rahibenin etnik kökeni hakkında yorum yapmayı engeller. Fakat tanrıçaya sunulan kişisel eşyalar veya rahibenin eşyaları arasında yer alan, onun felaket kehanetlerinin yaratılmasına zemin hazırlayarak mitosun oluşmasına katkı sunacak, Doğu kökenli ikonik bir obje veya kostümün belki de bir maskenin ayinlerde kullanıp kullanmadığı sorusu akla gelebilir. Dini törenlerde maske kullanılması Neolitik Dönem'e kadar giden uzun bir geçmişe sahiptir ve rahip/rahibeler bu maskeler sayesinde ritüel veya performanslar sırasında tanrı rolünü üstlenebiliyordu ${ }^{47}$. Nitekim Laumonier, Athena rahibesinin ayinlerde yüzünü erkeksi bir maske ile kapladığını ve sakallı rahibenin aynı zamanda tanrıçanın yansıması olabileceğini ileri sürerek, Pedasalı Athena'yı Babilli Iştar ve ondan türeyen Fenikeli Astarte ile ilişkilendirir ${ }^{48}$. Yukarıda bahsedilen Megiddo'da bulunan fildişi levhadaki boğa adam olarak yorumlanan boynuzlu, dışa kıvrık saçlı ve sakallı erkek figürlerinin başları basma kalıp tasvir edilmiştir ${ }^{49}$. Figürlerin bu şekildeki tasviri, bize dışa kıvrık tipik Hathor saçlı peruk, boynuz ve sakaldan oluşan bir tören maskesi takmış olabileceklerini düşündürür. Mezopotamya ve Fenike'de yaygın olan tanrıça Humbaba maskeleri ${ }^{50}$ özelinde, doğulu tanrıların kostüm ve eşyalarının Hellen dini ritüellerinde kullanılan, tanrıların kişisel gardroplarına ait eşyaları nasıl etkilediği daha önce Burkert tarafından ortaya konmuştur ${ }^{51}$. Yakın Doğu'daki tanrılar dünyasının görsellerinin kökeni, ortaya çıkış süreçlerindeki karmaşık kültürler arası etkiler ve Hellen dini ritüelleri üzerindeki etkileri bu çalışmanın odak noktası dışındadır. Ancak, Pedasa'da Hathor betiminin bulunması Athena - Hathor eşleşmesi için şimdilik yeterli olmasa da, MÖ IX. yüzyıla kadar geri giden Karia-Levant ${ }^{52}$ ilişkileri göz önüne alındığında "sakalı uzayan Athena rahibesi" söylencesinin oluşmasında Fenike aracılığıyla ulaşan Hathor veya özdeşi Anat ya da Astarte yorumlarının ve ayinlerde kullanılan maskelerin etkisi olduğu düşünülebilir.

\section{Kemik Kadın Başı}

Kutsal alan buluntuları arasında daha önce yayınlanan MÖ VII. yüzyılın üçüncü çeyreğine tarihlenen dedalik saçlı kadın başı, bir kere daha burada Hathor betimli levha ile beraber değerlendirilmeyi hak eder (Fig. 9) ${ }^{53}$. Mobilya apliği, sinek kovucu sapı ya da kadın formlu bir koku kabına ait olabilecek baş, özenli el işçiliğine sahiptir ${ }^{54}$.

47 Paulys Realencyclopädie der Altertumswissenschaft XXVIII (1930), 2070-2120, özellikle 2070-2072, s.v. Maske (M. Bieber); Lexicon der Ägyptologie III (1980), 1196 - 1199, s.v. Maske (C. Seeber); Foster 2016.

48 Laumonier 1958, 609. Ayrıca sakallı rahibe ve dolayısıyla sakallı tanrıçanın kökeni Šauška ve onun Yakın Doğulu özdeşlerine dayandırılmak istenir (bakınız Herda 2009b, 82, dipnot 310 - 312). Hitit tanrıçası Šauška için ayrıca bakınız Alexander 1991; Işık 2004, 511 - 512.

49 Loud 1939, 10, 14, no. 44, PI. 10 - 11; Alexander 1991, 162 - 163, Fig. 2.

50 Pedasa Athena rahibesinin dini ayinlerde özel bir maske veya kostüm kullanmış olabileceği ve Megiddo'daki fildişi levhadaki boğa adamların aslında Hathor saçıı sakalllı maske takmış olabileceklerini önerdiğimde dikkatimi "sedir ağaçlarının koruyucusu" Humbaba'ya çeken Dr. Alexander Herda'ya sadece bu hatırlatmadan dolayı değil cömert bilgi paylaşımı için ayrıca teşekkür ederim.

51 Burkert 1992, 20, 49, 100. Burkert, Sparta'da Artemis Orthia Kutsal Alanı'nda bulunan grotesk maskelerin Humbaba maskelerinin taklidi olduğunu ileri sürer. Ayrıca, Burkert bir diğer yayınında, Dionysos festivallerinde bir direğe asılan maskenin Mısır'daki Hathor dikmeleri gibi olduğunu söyler (Burkert 2003, 81 - 82).

52 Avishur - Heltzer 2003, 87-90.

53 Bulut 2013, 125-132, Res. 2.

54 Saray, kutsal alan veya mezarlardan gelen kanıtlar elitlerin kullandığı kaliteli mobilyaların bazılarının fildişi 


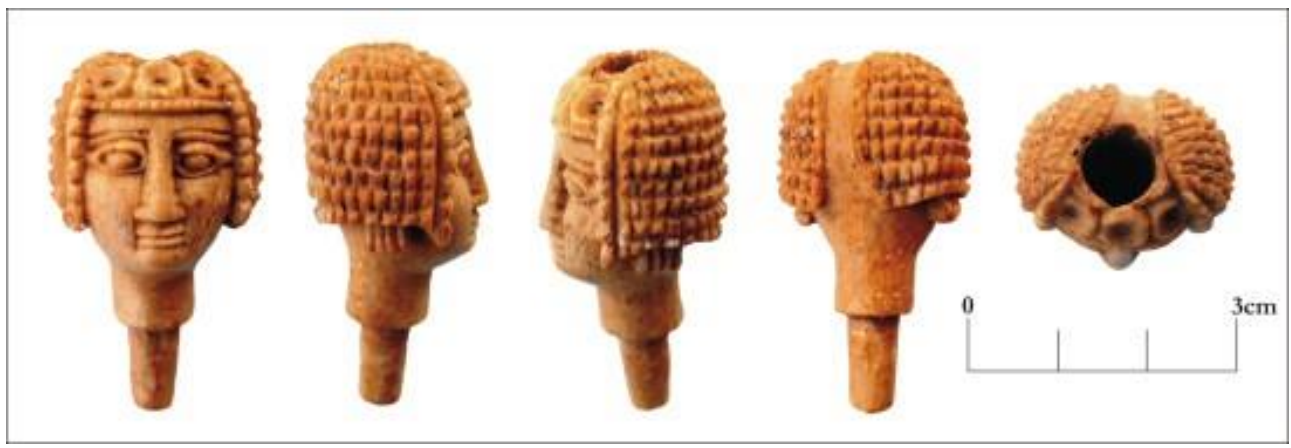

Fig. 9. Pedasa Athena Kutsal Alanı'ndan gelen kemik kadın başı (Bulut 2013)

MÖ XII. yüzyıla ait olmakla birlikte, Lachish'teki ${ }^{55}$ (Tell ed Duweir) tapınak buluntuları arasında yer alan kadın formlu fildişi koku şişesinde tıkaç işlevindeki kadın başı, Megiddo'dan ${ }^{56}$ gelen MÖ XIII. yüzyıla tarihlenen kısa peruklu başla birlikte Pedasa'daki kadın başının tipolojik kökeninin anlaşılmasına yardımcı olur. Ayrıca, Mısır ve Yakın Doğu'da yaygın olan, yüzen çıplak genç kız şeklinde saplara sahip kaşıklar arasında da peruk şeklinde benzer kısa saçlı versiyonlar çoğunluktadı ${ }^{57}$. Pedasa figürini, alında, alttan inci dizisi ile sınırlandırılan içleri olasılıkla farklı malzeme ile doldurulmuş rozetlerden oluşan alın bandı ve kulak başıklarıyla süslenmiştir ${ }^{58}$. Belirgin elmacık kemikli ve iri gözlü olan figür, küçük çenesi, geniş trapedoizal burnu ve ince dudaklarıyla tamamlanan katı yüz ifadesiyle Suriye - Fenike geleneğindeki fildişi betimlerini hatırlatır ${ }^{59}$ ve bu yüz ifadesi onu Hathor betimli levhalara yaklaştırır. Saçın şekillendirilmesinde Mısır etkileri görülmektedir. Saç boncuklar halinde özenle şekillendirilmiştir ve yüzü sınırlayan ilk tutamlar (zülüfleri) uzun tutularak geniş ve derin bir yivle diğerlerinden ayrılmıştır. Bu özenli ve incelikli saç şekli, Korinth ve Rhodos atölyelerinde üretilen pişmiş toprak vazolar üzerindeki tasvirlere de yansımıştır ${ }^{60}$. Pedasa örneğinde olduğu gibi, fildişi ve kemik oymalar üzerinde dolaylı

ornamentlerle zenginleştirildiğini ortaya koyar. Salamis’te ortaya çıkarılan fildişi süslemeli başlığıyla dikkat çeken ahşap karyola başlığındaki aplikler için bakınız Karageorghis 1973, 89 - 90, 92-95, PI. C-E, LXVI (Mezar 79). Samos Heraion'dan gelen ve mobilya apliği olarak yorumlanan kadın figürü için bakınız Brize 1992, PI. 1a-b. Sinek kovucu sapı olarak kullanılan insan figürleri için bakınız Barnett 1975, 213 - 217, PI. LXXXVIII - XCIV, no. S293-336. Lachish'ten gelen koku kabı ve Megiddo'dan gelen kısa saçı kadın başı için bakınız dipnot 55 ve 56 .

55 Koku kabının tıkacı olan figürün başına sıvıyı akıtmak için el şeklinde bir kaşık yerleştirilmiştir (Tufnell 1940, 59, PI. XV, no. 1; Decamps de Mertzenfeld 1954, 55-56, PI. III, no. 11a-12, PI.IV. no.11b; Barnett 1982, 28, Pl. 21.a; Fischer 2007, 251, Taf. 58, no.13).

56 The Illustrated London News 23/10/1937, 707, en üst soldan birinci; Loud 1939, 18, PI 44, no. 194; Loud 1939, 18, PI. 44, no. 194, Decamps de Mertzenfeld 1954, 81, PI. XXXII, no. 288; Fischer 2007, 318-319, Taf. 96, no. 7.

57 Fischer 2007, 277-339 (kısa saçlı örneklerden bir kaçı için Taf. 95.a; Taf. 99-100. L8-L10; Taf. 102-103. L1819, L21, Taf. 104-107. L24-25, L29, L32, L33, 35-36; Taf. 109-114. L41-42, L44, L48-49, L51-54, L56; Taf. 117. L64; Taf. 119-121. L72. Genellikle su dalgası halinde şekillendirilen saçlar arasında, Fischer 2007, Taf. 109. L41-42'deki örnekler Pedasa başında olduğu gibi boncuklar halinde şekillendirilmiştir.

58 Bulut 2013, 128-129, dipnot 22-23. Yakın Doğu fildişi ve kemik oymalarının canlılığını arttırmak için altın, gümüş, renkli cam veya pişmiş toprak dolgu veya kaplamalar kullanılıyordu.

59 Benzer ifadenin olduğu birkaç örnek için bakınız Barnett 1975, 205 - 207, PI. LXX, S172 - 73, 183; LXXI, S175, 181-182; LXXII, S190-199, özellikle S198. Nimrud'daki Suriye geleneğindeki fildişi kadın başları arasında göz çevresi ve kaşları oyuk örnekler için Barnett 1975,191-193, PI. XXII, S4 (pyksis); PI. XXII, S8, 26, 28 (pyksis); 205-206, PI. XXVI S20; PI. LXX, S172-174, S183-185.

60 Protokorinth Dönemi'nin titiz ressamlarından biri olan Aegina Bellerophon Ressamı'nın sphinks ve insan figürlerinde ilk saç tutamlarının (zülüflerin) aynı şekilde ayrılması fildişi oymacılığı ile çağdaşı vazo ressamlığı arasındaki etkileşimin örneklerinden birini ortaya koyar (Amyx 1988, 28, 368, PI. 8,1a-c [Aegina 
olarak Mısır sanatının izleri görülse bile, gerçek Mısırlı ürünler Hellen dünyasında seyrek olmasına rağmen yine de büyük oranda Ege'nin güneydoğusundan geldiklerini söylemek gerekir $^{61}$.

\section{Üretim Yeri ve Köken}

Pedasa, Didyma ve Kamiros'tan gelen levhalar yukarıda da bahsedildiği gibi ahşap mücevher kutusunun kaplamaları olmalıdır (Fig. 4a-c). Levhaların ikonografik detayları ve kazıma çizim stilleri tek bir prototipin etkisi altında aynı atölyede üretilmiş olduklarını açıkça ortaya koyar. Levhalar, Mısır panteonunun önemli tanrılarından birinin tasvirini taşımasından dolayı ilk bakışta Mısır kökenli gibi algılanmakla birlikte yüzlerde, özellikle trapezoidal geniş kanatı burun çizimlerinde Fenike özelliği dikkati çeker. Ayrıca kazımalar, Ephesos Artemision'dan gelen Astarte ile ilişkilendirilen ve Fenike işi olarak kabul edilen levhalardaki derin ve tutuk çizim karakteriyle uyumlu bir birliktelik sergiler (Fig. 6). Schofield, Papatislures levhalarının Mısır kökenli Hathor sistrumundan ilham alınarak Rhodoslu fildişi ustaları tarafından üretilmiş olabileceğini ileri sürer $^{62}$. Fakat Mısır kökenli yabancı bir tanrıçanın betiminin kullanııması ve de az sayıda olmaları, daha ziyade onların dışarıdan getirilmiş olabileceklerini gösterir. Eğer levhalar Rhodos'ta üretilmiş olsaydı en azından yakın coğrafyada sayılarının biraz daha fazla olması ya da üretimlerinde yerel zevki yansıtan bir kaç öğeye sahip olmaları beklenirdi. Arkeolojik ve epigrafik veriler, Fenikelilerin Ege'de MÖ geç IX. yüzyıldan itibaren varlığı ve giderek artan ticari faaliyetlerine dair güçlü kanıtlar ortaya koyar ${ }^{63}$. Başta Dunbabin ve Coldstream olmak üzere pek çok araştırmacı tarafından Ege dünyasında, özellikle Girit, Atina ve Rhodos'ta Fenikeli veya doğulu göçmen zanaatkarların yerleşik olduğu tartışılmıştı ${ }^{64}$. Girit'te ortaya çıkarılan bronzlar, fildişi oymalar ve Rhodos fayans ve fildişlerinin doğulu göçmen ustaların kurduğu atölyelerde onların yetiştirdiği yerli

K 253]. Kamiros'tan yayınlanan plastik aryballos, sadece Pedasa saç tasarımı ve Lachish kadınının yüz anatomisinin benzerini göstermekle kalmaz aynı zamanda MÖ VII. yüzyıl ikinci yarısında Rhodoslu çömlekçilerin Doğu kökenli lüks ürünlerin çok yakın pişmiş toprak versiyonlarını üretmedeki yeteneklerini ortaya koyar (Barnett 1948, 17, PI. XII, a-b; Ducat 1966, 155, PI. XXIII, no.1 (MÖ 640-630).

61 Mısır kökenli fildişi ve kemik oymalar Kuzey Suriye - Fenike kökenli örneklerle karşılaştıııldığında da çok az sayıdadır (Sakellarakis 1993, 355-356, 359). Girit, İda Mağarası: Kunze 1935-1936, 231, no. 8a-c, PI. 84A (bir veya iki yüzü kazıma bezemeli levha parçalardan 8b'nin arka yüzünde hieroglif); Samos Heraion: Freyer-Schauenburg 1966, 11-12, 111-118, no. 29 (E79), Taf. 32a (çıplak kadın figürlü tutamak), no. 30 (E73), Taf. 33 (Hathor başlığı), no. 31-32, Taf. 34a-b (skarabe); Lindos Athena: Blinkenberg 1931, 149, PI. 15, no. 419 (ördek başlı kaşık sapı).

62 Schofield 1992, 176 - 177; Matthäus 2009, 323.

63 Ege dünyasında, Fenike kökenli lüks ithal ürünler dağınık olarak MÖ X. yüzyıldan itibaren görülmeye başlar. Fenike kıyı kentlerinden gelen değerli metal ve fildişi lüks mallar, organik ürünler ve günümüze ulaşmamış olmakla birlikte zengin tekstil dokumalar dışında bir diğer fenomen ise Kommos'ta (Girit) MÖ 800 'lerde Fenikeli denizciler tarafından veya onların dini inanışları etkisi altında inşa edilen kutsal alan ve MÖ. VIII. yüzyıl sonundan itibaren Arkaik Dönem'de Doğu Ege'de belirli merkezlere (özellikle Girit, Rhodos, Kos) yerleşen "göçmen yabancı ustalar veya tüccarlar" (metkoikoi) ve tesis ettikleri atölye/atölyeler etrafında şekillenen kokulu yağ/krem üretimi ve ticari dağılımları için gerekli akıtacaklı şişeler ve lüks el sanatları endüstrisidir. Bakınız Blinkenberg 1931, 41-42; Dunbabin 1957, 38-41, 49; Coldstream 1969, 1-8; Coldstream 1982, 268-269, 272; Shaw 1989, 165-183; Jones 1993; Kourou 2003; Stampolidis - Kotsonas 2006, 337-355; Kourou 2008, 305-357; Bourogiannis 2013; Kourou 2015, 252-256.

64 Barnett 1948, 1-17; 1956, 236; Dunbabin 1957, 40-43; Boardman 1967, 63-67; 1980, 56-64; Murray 1980, 82; Burkert 1992, 21-22. Muhly, Geç Bronz Çağ Yakındoğu yazılı kaynaklarına dayanarak metal, fildişi, heykel veya seramik üretiminde usta zanaatkarların sarayın denetiminde çalıştıkları ve yabancı ülkelere gidişlerinin ancak resmi krali yazışma ile mümkün olabildiğini ve yüksek kaliteli üretim yapan ustaların kendi insiyatifleriyle bir yerden başka bir yere gidip üretim yapamayacaklarını ileri sürer (Muhly 2006, 685-690). 
ustalar veya sonrasında Hellenleşmiş ardılları tarafından üretildiği ileri sürülmüştür ${ }^{65}$. Fakat Doğu Ege'ye ulaşan az sayıdaki Hathor betimli kaplama levhası ve Pedasa'daki kadın başının stilistik özellikleri, onların Fenike kökenli bir atölyenin ürünleri olarak değerlendirilmeleri gerektiğini işaret eder. Bilindiği gibi, MÖ VIII. yüzyıl sonlarında Asur'un Levant'taki zengin üretim ve ticari merkezler (Tyre, Sidon, Byblos gibi) üzerindeki baskısı Fenikelilerin ticari ağırlığını Akdeniz'e kaydırmasına neden olur. Bu dönemde Fenike kıyı kentlerinde ortaya çıkan yeni atölyelerin Mısır stili ve ikonografisinin etkisi altındaki üretimleri tüm Akdeniz'e dağııır ${ }^{66}$. Fenike kentleri sadece kendi üretimlerini değil aynı zamanda iç kesimlerde Mezopotamya'dan gelen lüks ürünlerin dağııımında da Kıbrıslı tüccarlarla birlikte söz sahibiydiler. Bu çerçevede, kemik levhalar ve Pedasa kadın başı, Fenikeli veya onların ticari ortakları sayesinde Doğu Ege merkezlerine ulaşmış olabilir. Levhaların, özellikle Pedasa ve Didyma'dakinin kutsal alana sunulmasının arkasındaki bir diğer alternatif senaryo ise değerlendirme bölümünde aktarılmıştır.

\section{Değerlendirme}

Tunç Çağ’ın sonundaki çöküşle birlikte Akdeniz dünyası, ticari ve kültürel iletişim açısından puslu bir sürece girer. MÖ X.-IX. yüzyıllarla birlikte ilişkiler tekrar kurulurken başlangıçta buluntular dağınıktır ve çoğunlukla mezarlardan elde edilir; MÖ IX. yüzyıl sonu - VIII. yüzyıldan itibaren ise kutsal alanlardan gelen verilerde artış görülür ${ }^{67}$. MÖ VIII.- VII. yüzyıllar boyunca Ege dünyasına ulaşan, Doğu kökenli metal eserler, sofistike fildişi ve kemik oymalar, fayanslar, tridachna ve renkli tekstillerin erken Hellen sanatının şekillendirilmesindeki rolü önemlidir ${ }^{68}$. Kutsal alanlarda ortaya çıkarılan bu eşyaların nasıl ve kimler tarafından sunulduğu ise uzun bir araştırma geçmişine ve literatüre sahiptir. Ağırlıklı olarak, Mısır ve Yakın Doğu'ya seyahatlerinden ana yurda dönen büyük bir kısmı elit sınıftan olan tüccar, korsan veya paralı askerler tarafından adandıkları veya ekonomik ve siyasi ilişkilerin tesisi sırasında diplomatik hediyeler olarak kutsal alanlara gönderildikleri kabul edilir ${ }^{69}$.

Pedasa Athena Kutsal Alanı́nın doğu temasları esas olarak iki coğrafya ile gerçekleşir; Mısır ve Yakın Doğu. Yazılı kaynaklar ve arkeolojik veriler, 26. Hanedan Dönemi'nde MÖ VII. yüzyıl ortalarına doğru başlayan Mısır Ionia/Karia ilişkilerinin MÖ VI. yüzyılda yoğunlaştığını ortaya koyar $^{70}$. MÖ VII. yüzyılın ortalarından itibaren Mısır'a yerleşen Karialı paralı askerler, askeri hünerlerinden ve çift dilli olmalarından dolayı yüksek statü elde ederek elit gruplar içinde yer alırlar ${ }^{71}$. Paroslu Arkhilokhos'un MÖ VII. yüzyıl ortalarındaki şiirinde Karialı ile "paralı asker" kelimesini eş anlamlı olarak kullanması, Karialıların Akdeniz'deki en iyi paralı askerler olduğunu düşündürür ${ }^{72}$. Herodotos (II. 152-154), Diodoros (I. 66. 12-67. 2) ve Polyainos (Stratagemata VII. 3)

65 Barnet 1948, 17; Dunbabin 1957, 38-41, 49, 55; Carter 1985, 287-288; Schofield 1992, 173, 177; Sakellarakis 1993, 360-361; Hoffman 1997, 148, 156-160; Martinelli 2000, 114.

66 Kourou 2015, 252-253, dipnot 49.

67 de Salvia 1991; Strøm 1992; Sakellarakis 1993, 346-348; Kilian - Dirlmeier 1985; Kilian - Dirlmeier 2000; Hölbl 2005; Hölbl 2007.

68 Barnett 1956; Dunbabin 1957, 44-49; Boardman 1980, 54-84; Matthäus 2009.

69 Kyrieleis 2009; Niemeier 2016; Kaplan 2002.

70 Petrie 1886, 7-34; Austin 1970, özellikle 15-70; Llyod 1975, 1-60; Boardman 1980, 111-139; Haider 1996, 95-113; Möller 2000, 32-38; Haider 2001; Kammerzell 2001; Kaplan 2002, 237 - 241; Vittmann 2003, 155-179, 194-235; Haider 2004; Höckmann - Vittman 2005; Boardman 2006, 524-531; Williams-Villing 2006, 47-48; Hölbl 2007, 447-449; Höckman 2012, 456-476.

71 Herda 2013, 468.

72 Niemeier 2001, 17; Kaplan 2002, 233; Herda 2013, 447 (Karialıların askeri becerisi ve silahları için Herda 2013, $442-447)$. 
Mısır üzerindeki otoritesini yerleştirmek isteyen I. Psammetikhos'un (MÖ 664-610) Karialıları paralı asker olarak hizmetine aldığını söyler. Antik yazarlara göre firavun, vaat ettiği ödülleri vererek emrindeki paralı askeleri Nil deltasının doğusunda kurduğu kamplara (Stratopeda) yerleştirir. Hatta Polyainos, bu yüzden Memphis'in bir bölümünün "Cariomemphitae" olarak adlandırıldığını söyler (Stratagemata VII. 3) ${ }^{73}$. Polyainos, Karialı Pigres'in, Tementhes'i Memphis'te yendiği savaşta Psammetikhos'un danışmanı olduğu da aktarır. Nitekim Memphis'te bulunan Pigres'in mezar stelinin Polyainos'un bahsettiği Pigres'e ait olduğu ileri sürülmüştür ${ }^{74}$. Mısır'dan anavatanına geri dönen komutan Pedon tarafından adanan Priene civarından gelen heykeldeki yazıt, kahramanlığı ve erdeminden dolayı Psammetikhos'un kendisine hediye ettiği kentten bahseder ${ }^{75}$. Abu Simbel'deki yazıta göre, Karialı ve Hellen paralı askerler II. Psammetikhos'un (MÖ 595-589) Nubia seferindeki askeri birliklerinde de yer almışlardır ${ }^{76}$. Apries MÖ 570'te Amasis'e karşı yürüdüğünde, ordusunda 30.000 Karialı ve Ionialı asker yer almaktaydı. Herodotos başlangıçta Karialı ve Hellenlerin Mısır’a kazara ulaştığını söylese de kabul edilen genel görüş onların Lydia kralı Gyges tarafından gönderildiğidir ${ }^{78}$. Asurbanipal'in yıllıkları da Lydia Kralı Gyges'in Psammetikhos'a yardım etmek üzere birlikler gönderdiğini teyid eder ${ }^{79}$. Saqqara'daki mezar stelleri ${ }^{80}$, Sais'te ${ }^{81}$ bulunan bronz objeler üzerindeki şu ana kadarki Mısır'daki en eski Karca yazıtlar, Abu Simbel'de ${ }^{82}$, Naukratis'ten ${ }^{83}$ yayınlanan Karia kökenli seramik parçası ve daha başkaları Mısır'da yerleşik Karialıların güçlü kanıtlarını sunar ${ }^{84}$.

Bu çerçevede, MÖ VIII. yüzyıldan itibaren başlayan Mısırlı objeler veya onların Fenike taklitlerinin Ionia ve Karia merkezlerine girişinin MÖ VI. yüzyıl ortalarına kadar devam ettiği görülür ${ }^{85}$. Buluntular, çoğunlukla skarabe, nazarlık ve küçük koku şişelerinden oluşan ve hemen hemen tüm merkezlerde birbirini tekrarlar nitelikteki fayanslar ${ }^{86}$ veya Samos Heraion' da ${ }^{87}$ olduğu gibi bronz heykelcik veya objelerden oluşur. Athena'ya sunulan ve büyük bir olasılıkla Naukratis üretimi olan fayans sunular ${ }^{88}$ ve fildişi heykeliciğe ait yayınlanmamış kol parçası ${ }^{89}$, MÖ VII. - VI. yüzyıl arasında Pedasalıların Mısır ile kurduğu bağlantıları gösterir. Söz konusu fayanslar, Mısır yaşam kültürü ve dini inanışlarına entegre olan Pedasalılar veya aileleri tarafından anavatana dönüşlerinde tanrıçaya sunulmuş olmalıdır ki, Mısır'da görev yapan Karialı (veya Ionialı) askerlerin kendilerine tahsis edilen kamplarda yerleşip Karialı veya Mısırlı kadınlarla

73 Vittman 2003, 156; Herda 2013, 468 (Karikon), dipnot 242.

74 Kammerzell 2001, 240-241, 246, Abb. 2.1 (Brüksel E 2483); Niemeier 2001, 17; Adiego 2007, 36, E. Me 3.

75 Şahin 1987, 1-2, Taf. 1; Masson - Yoyette 1988, 171-180, Taf. 25.

76 Boardman 1980, 115-117.

77 Boardman 1980, 117.

78 Boardman 1980, 115.

79 Niemeier 2001, 17-18.

80 Kammerzell 2001, 233-255; Vittmann 2003, 161-179; Adiego 2007, 34-74; Herda 2009a, 72-73, Abb.4a-b; 2009b, 76.

81 Adiego 2007, 32-33, E.Sa 1-2 (I. Psammetikhos Dönemi MÖ 664-610).

82 Vittmann 2003, 163, Abb. 78; Adiego 2007, 115 - 119, E. AS 1-9.

83 Williams - Villing 2006, 47, Fig. 2.

84 Adiego 2007, 30 -128.

85 Hölbl 2007.

86 Başlıca Pendlebury 1930; Webb 1978; Hölbl 2005; Webb 2016.

87 Jantzen 1972, 5-37, Taf. 1-36; Niemeier 2016, 239-245.

88 Bulut 2018a. Arkaik Dönem'de Karia Bölgesi'nde Mısır bağlantılı fayans sunuların adandığı bir diğer kutsal alan ise Knidos'taki Apollon Kutsal Alanı'dır (Berges 2006, 183-186; Taf. 112-116; Tuna 2012, 87-88, Şek. 91-92).

89 Samos Heraion'dan gelen, kollarını dirsekten kırarak ileri uzattıkları ellerinde obje tutar halde betimlenen benzer pozdaki Mısır bronz heykelcikleri için Jantzen 1972, Taf. 4. B 160, L 12.5; Taf. 5. 
evlendikleri ya da en azından beraber yaşadıklarını ileri süren kanıtlar mevcuttur ${ }^{90}$.

Mısır'da olduğu gibi büyük kafileler halinde olmasa da, Hellen veya Karialı tüccar, korsan, paralı asker, taş ustası ya da kahramanlık ve ün peşindeki maceracı ruhlu sürgün elitlerin varlıkları Yakın Doğu'da da kanıtlanmaktadır ${ }^{91}$. İsrail yazııı kaynakları, Megiddo ve Samaria'dan gelen en eski Karca harfleri gösteren taş ustası işaretleri, MÖ IX. yüzyıldan itibaren Akdeniz'in doğusunda Karialıların olduğunu kanıtlar ${ }^{92}$. Paralı asker olarak Hellenlerin ise ilk olarak MÖ VIII. yüzyılda geldikleri, MÖ VII. yüzyılda Levant'ta başlıca Asur, Babil, Judah Kralığı ve Tyre tarafından istihdam edildikleri kabul edilir ${ }^{93}$. MÖ VIII.- VII. yüzyıl başlarına ait Asur kaynaklarında bahsedilen, Akdeniz' den gelen ve "Ionialılar" olarak adlandırılanların rolü tam olarak bilinmiyor olsa da genel görüş Asur ve onların tehdidi altındaki devletler tarafından tutulan paralı askerler olabilecekleridir $^{94}$. Antik metinlere göre Babil ordusunda görev olan, Mytileneli şair Alkaeus'un kardeşi Antimenidas, bazılarına göre Babil'in MÖ 604 yılında Askhelon'u ele geçirdiği sırada ordu saflarındaydı ve hatta MÖ erken VI. yüzyılda Judah Krallığı'na karşı olan seferde yer almıştı ${ }^{95}$. Babil kralı II. Nebukadnezzar’ın Tyre kuşatmasının (MÖ 603-585) başlamasından önce Tyre birliklerindeki yabancı paralı askerler arasında Karialı ve Hellenlerin olduğu da ileri sürülür ${ }^{96}$. Tarsus, Al Mina, Tell Sukas, Ras el-Basit ve Tyre'den gelen seramik buluntular Hellenlerin MÖ VIII. yüzyıldan itibaren Yakın Doğu'daki faaliyetlerinin arkeolojik kanıtlarını sunar ${ }^{97}$. Tel Kabri ve Meşad Haşhavyahu'dan gelen, ticari amphoralar, pişirme kapları ve kandillerden oluşan seramikler Hellen paralı askerlerin varlığılla ilişkilendirilir ${ }^{98}$. Tel Kabri'dekilerin MÖ 600'den kısa bir süre sonra Tyre (Fenikeliler) tarafından tutuldukları genel olarak kabul edilmekle birlikte Meşad Haşhavyahu'dakilerin Mısır ya da Judahite ordusunda yer aldıkları yönünde farklı görüşler vardır ${ }^{99}$. Tel Batash/Timnah II. tabakadaki çok az sayıdaki mutfak kabı da yine Hellen paralı askerlerle ilişkilendirilir ${ }^{100}$. Adı geçen bu merkezlerdeki paralı askerler arasında Karialı Hellen ayrımını yapmak güçtür. Fakat bireysel savaş taktiklerindeki hünerleri dolayısıyla Ionia ve Karia'da uzun dönemler iç içe yaşayan Karialıların da giden gruplar arasında olması beklenir ${ }^{101}$. Arkaik Dönem'de Yakın Doğu'daki paralı askerlerin silah ve ekipman olarak arkeolojik kanıtlarına gelince; sadece Kargamış'tan MÖ VII. yüzyıl ikinci yarısına ait Gorgo başıı bronz kalkan ve baldır

90 Saqqara'dan gelen Karialı evli bir çifte ait MÖ VI. yüzyılın ikinci yarısına tarihlenen mezar steli için bakınız Kammerzell 2001, 253, Abb. 12.1(Cambridge, Fitzwilliam Museum E. 1.1971 [M-23]); Adiego 2007, 43, E. Me 11; Herda 2009a, 72-73, Abb.4a-b; Herda 2009b, 76; Austin 1970, 19-20; Haider 1996, 111; Möller 2000, 34. Austin, Hellen ve Karialı paralı askerlerin belli durumlarda Mısırlı yerli kadınlarla evlilik haklarına sahip olması gerektiğini destekleyici fikir öne sürerken Llyod ve Boardman Mısır’da evlilik haklarına ilişkin herhangi bir kanun olmamasına rağmen aksi yönde görüş bildirir (Llyod 1975, 19-20; Boardman 2006, 531). Mısır’ın Makedon hakimiyetini girdiği dönemde Hellen paralı askerlerin Mısırlı kadınlarla evlendikleri de bilinmektedir (Llyod 1975, 20, dipnot 73-74).

91 Niemeier 2001; Boardman 2006, 510-523; Luraghi 2006; Herda 2009a, 61; Niemeier 2016, 241-242.

92 Avishur - Heltzer 2003, 87-90; Herda 2009a, 61; 2013, 458.

93 Niemeier 2001.

94 Niemeier 2001, 16-17.

95 Niemeier 2001, 18; Boardman 2006, 523. Fantalkin - Lytle ise Antimenidas'ın II. Nebukadnezzar'ın ordusunda pararlı asker olarak görev yaptığına şüpheyle yaklaşır ve buradan Neo-Babil ordusunda Hellen paralı askerlerin düzenli istihdam edildiği sonucunun çıkarılamayacağını savunur (Fantalkin - Lytle 2016). Niemeier 2001, 18-19.

97 Boardman 1980, 39-54; Boardman 2006, 513-518.

98 Niemeier 2001, 12-16; 21-24; Boardman 2006, 523.

99 Niemeier 2001, 23; Boardman 2006, 523.

100 Niemeier 2001, 23.

101 Herda 2009a. 
zırhından oluşan iki tane Hellen silahı bilinmektedir ${ }^{102}$. Ayrıca Hellen hoplit betimleri Amathus'tan gelen MÖ geç VIII. - erken VII. yüzyıla tarihlenen Kıbrıs-Fenike gümüş kasesinde yer alır ${ }^{103}$. Tasvirde, Hellen hoplitler hem Fenike şehrine saldıran Asurlu süvari ve okçular tarafında hem de kenti savunan askerler arasında görülürler.

Zaferle sonuçlanan uzak mesafeli seferlerin dönüşünde kutsal alanlara adanan eşyalar, kişilerin sosyal statülerine göre değişirken yapılan sunular bireylerin toplumdaki yeri ve saygınlığının artırılmasına katkı sağlar. I. Psammetikhos'un askeri birliklerindeki başarısından dolayı ödüllendirilen Pedon Ionia'ya geri döndüğünde adadığı heykelle ${ }^{104}$ bir taraftan tanrılara minnetini gösterirken diğer taraftan elde ettiği prestiji toplumda geniş bir kitleye ilan ederek saygınlığını artırır. Sonuç olarak, Pedasa'dan gelen Fenike kökenli Hathor betimli levha parçası ve kadın başı, ticari ilişkiler sonucu bölgeye ulaşmış olabileceği gibi MÖ VII. yüzyılda paralı asker veya taş ustası olarak Doğu Akdeniz'e giden Karialılar veya aileleri tarafından yurtlarına güvenle döndüklerinde, şükran sunusu olarak da Athena'ya adanmış olabilir. Bu senaryo, Didyma Apollon Tapınağı'ndan gelen kemik levha için de olasılık dahilindedir ki Apollon'a sunulan ve bir kısmı Taxiarchis Tepesi'nden gelen eşyalar arasında, MÖ VII. -VI. yüzyıla ait Doğu kökenli ok uçları lonialı askerlerin sunuları olarak yorumlanmışıı ${ }^{105}$. Ayrıca, şimdilik yeni kanıtlarla desteklenmeye ihtiyaç duymakla birlikte Pedasa Athena rahibesi ile ilgili söylencenin ortaya çıkmasında Fenike aracılığıyla ulaşan Hathor ve eşdeğer tanrıçaların tasvirlerinin ve de ayinlerde kullanılan Yakın Doğu kökenli kostüm veya maskelerin etkisi olduğunu düşünebiliriz. Burada aydınlatılması gereken gereken bir diğer nokta ise Karialının adağını tanrıça Hathor'u benimseyen ve onun kültüne entegre olmuş bir mürid olarak mı; yoksa basit anlamda sadece dekoratif unsuru olan bir eşya olarak mı Pedasalı tanrıçaya sunduğudur.

102 Boardman 1980, 51, Fig. 20; Niemeier 2001, 19-20, Fig. 2-3; Boardman 2006, 521; Niemeier 2016, 242 (Zırh ve kalkanı kullanan askerlerin Mısırlı II. Necho'nun MÖ 606/604'te kenti kuşatan birliklerinde yer aldığı kabul edilir).

103 Boardman 1980, 50, Fig. 19.

104 Şahin 1987, 1-2, Taf. 1; Masson - Yoyette 1988, 171-180, Taf. 25. Antik metinlerde ve arkeolojik kaynaklarda bu tür prestij sunularının örnekleri çoğaltılabilir; Herodotos Samoslu kaptan Kolaios'un eve dönüşünde Hera'ya zengin hediyeler sunduğundan bahseder (IV. 152). Kazılardan ele geçen batı Fenike işi tarakların bazılarının Kolaios'un Tartessos'tan getirmiş oldukları arasında olabileceği ileri sürülür (Niemeier 2016, 241).

105 Lubos 2009, 405-414, Taf. 1.1-13. Didyma Apollon Tapınağı'na sunulan çoğunluğu ok ucu ve mızrak uçlarından oluşan aralarında miğfer, zırh ve kalkanların da olduğu silah sunuları ve Ionia kutsal alanlarından gelen diğer örnekler için Verčík 2017. 


\section{BIBBLIYOGRAFYA}

Adiego 2007

Adıgüzel 2013

Alexander 1991

Amyx 1988

Anderson 1976

Austin 1970

Avishur - Heltzer 2003

Bammer 1985

Bammer 1992

Baran 2017

Barnett 1948

Barnett 1956

Barnett 1975

Barnett 1982

Ben-Tor 2009

Berges 2006

Bleeker 1973

Blinkenberg 1926

Blinkenberg 1931

Boardman 1962

Boardman 1966

Boardman 1967

Boardman 1973

Boardman 1980

Boardman 2006

Bourogiannis 2013
I. J. Adiego, The Carian Language. Leiden \& Boston 2007.

G. Adıgüzel, Karia Bölgesi Buluntusu Athena Yontuları. Yayınlanmamış Yüksek Lisans Tezi, Muğla Sıtkı Koçman Üniversitesi. Muğla 2013.

R. L. Alexander, "Šaušga and the Hittite Ivory from Megiddo". JNES: Journal of Near Eastern Studies 50.3 (1991) 161-182.

D. A. Amyx, Corinthian Vase-Painting of Archaic Period. Vol.I-III. Berkeley 1988.

R. D. Anderson, Catalogue of Egyptian Antiquities in the British Museum III. Musical Instruments. London 1976.

M. M. Austin, Greece and Egypt in the Archaic Age. Proceedings of the Cambridge Philological Society. Supplement 2. Cambridge 1970.

Y. Avishur - M. Heltzer, "Carians as Skilled Masons in Israel and Mercenaries in Judah in the Early I Millenium B.C.E.". Kadmos 42 (2003) 87-90.

A. Bammer, "Spuren der Phöniker im Artemision von Ephesos". Anatolian Studies 35 (1985) 103-108.

A. Bammer, "Ivories from the Artemision at Ephesus". Ed. J. L. Fitton, Ivory in Greece and the Eastern Mediterranean from the Bronze Age to the Hellenistic Period. British Museum Occasional Paper 85. London (1992) 185-204.

A. Baran, "Pedasa Akropolis Suru Koridorlu Güney Geçidi". Cedrus V (2017) $121-129$.

R. D. Barnett, "Early Greek and Oriental Ivories". JHS: The Journal of Hellenic Studies 68 (1948)1-25.

R. D. Barnett, "Ancient Oriental Influences on the Archaic Greece". Ed. S. S. Weinberg, The Aegean and the Near East: Studies Presented to Hetty Goldman on the Occasion of her Seventy-fifth Birthday. New York (1956) 212-238.

R. D. Barnett, A Catalogue of the Nimrud Ivories with Other Examples of Ancient Near Eastern Ivories in the British Museum². London 1975.

R. D. Barnett, Ancient Ivories in the Middle East and Adjacent Countries. Qedem 14. Jerusalem 1982.

A. Ben-Tor, "A Decorated Jewellery Box from Hazor". Tel Aviv 36 (2009) 5-67.

D. Berges, Knidos. Beträge zur Geschichte der archaischen Stadt. Mainz am Rhein 2006.

J. C. Bleeker, Hathor and Thoth. Two Key Figures of the Ancient Egyptian Religion. Leiden 1973.

Chr. Blinkenberg, Fibules Greques et Orientales. Lindiaka V. Kopenhag 1926.

Chr. Blinkenberg, Lindos. Fouilles de L'Acropole 1902-1914. I. Les Petits Objets. Berlin 1931.

J. Boardman, "Archaic Finds at Knossos". BSA: The Annual of the British School at Athens 57 (1962) 28-34.

J. Boardman, "Part III. The Other Finds". Eds. J. Boardman - J. Hayes, Excavations at Tocra 1963-1965. The Archaic Deposits I. Oxford (1966) 151-167.

J. Boardman, "The Khaniale Tekke Tombs II". BSA: The Annual of the British School at Athens 62 (1967) 57-75.

J. Boardman, "A. Archaic Deposits: 4. The Other Finds". Eds. J. Boardman- J. Hayes, Excavations at Tocra 1963-1965. The Archaic Deposits II and Later Deposits. Oxford (1973) 75-85.

J. Boardman, The Greek Overseas. Their Early Colonies and Trade. London 1980. J. Boardman, "Greeks in the East Mediterranean (South Anatolia, Syria, Egypt)". Ed. G. R. Tsetskhladze, Greek Colonization. An Account of Greek Colonies and Other Settlements Overseas. Leiden \& Boston (2006) 507-534.

G. Bourogiannis, "Who hides behind the pots? A Reassesment of the Phoenician Presence in Early Iron Age Cos and Rhodes". ANES: An Annual 
Brize 1992

Bulut 2012

Bulut 2013

Bulut 2014a

Bulut 2014b

Bulut 2016

Bulut 2018a

Bulut 2018b

Bumke 2008

Burkert 1992

Burkert 2003

Carbillet 2011

Carter 1985

Cluzan 2008

Coldstream 1969

Coldstream 1982

Coulié 2014

Courtois 1984

Courtois - Lagarce 1986

Çur 2014

Dawkins 1929

Decamps de Mertzenfeld 1954
Published by School of Fine Arts. Classical Studies and Archaeology 50 (2013)139-189.

P. Brize, "New Ivories from the Samian Heraion". Ed. J. L. Fitton, Ivory in Greece and the Eastern Mediterranean from the Bronze Age to the Hellenistic Period. British Museum Occasional Paper 85. London (1992)163-172.

H. Bulut, "Kutsal Alan: Tapınak Terası". A. Diler, B. Özer, H. Bulut, Ş. Gümüş, "Pedasa, 2010". KST: Kazı Sonuçları Toplantısı 33/4 (2012) 171-172.

H. Bulut, "Pedasa'da Bulunan Bir Kemik Heykelcik". Arkeoloji ve Sanat 142 (Ocak-Nisan 2013) 125-132.

H. Bulut, "Early Iron Age Pottery from Halicarnassian Peninsula: Two New Amphora Fragments from Pedasa". OLBA XXII (2014) 63 - 79.

H. Bulut, "Kutsal Alan Tapınak Terası". A. Diler et.al, "Pedasa 2011-2012". KST: Kazı Sonuçları Toplantısı 35/3 (2014) 531-533.

H. Bulut, "Athena Kutsal Alanı: Tapınak Terası". A. Diler et.al, "Pedasa 2014". KST: Kazı Sonuçları Toplantısı 37/3 (2016) 560 - 562.

H. Bulut, "Pedasa Athena Kutsal Alanı Arkaik Dönem Fayans Adak Sunuları". TÜBA-AR: Türkiye Bilimler Akademisi Arkeoloji Dergisi 22 (2018) 119-143.

H. Bulut, "Dolphin Ressamı: Horozlu Alabastron'larına Doğu Ege'den Yeni Ekler". Arkeoloji ve Sanat 157 (Ocak-Nisan 2018) 83-94.

H. Bumke, "Zeugnisse für Kulturtransfer aus dem archaischen Apollonheiligtum von Didyma". Eds. R. Bol- U. Höckmann- P. Schollmeyer, Kult(ur)kontakte. Apollon in Milet/Didyma, Histria, Myus, Naukratis und auf Zypern. Akten der Table Ronde in Mainz vom 11.-12 März 2004. Rahden/ Westf. (2008) 87-96.

W. Burkert, The Orientalizing Revolution. Near Eastern Influence on Greek Culture in Early Archaic Age. Cambridge \& London1992.

W. Burkert, Die Griechen und der Orient von Homer bis zu den Magieren. München 2003.

A. Carbillet, La figure hathorique à Chypre (II $-l^{\text {er }}$ mill. av. J.-C). Alter Orient und Altes Testament Band 388. Münster 2011.

J. Burr Carter, Greek Ivory Carving in the Orientalizing and Archaic Periods. New York 1985.

S. Cluzan, "Cyprus: an International Nexus of Art and Trade". Eds. J. Aruz - K. Benzel - J. M. Evans, Beyond Babylon. Art, Trade, and Diplomacy in the Second Millenium B.C. New Haven \& London (2008) 311-383.

J. N. Coldstream, "The Phoenicians in Ialysos". BICS: Bulletin of Institute of Classical Studies 16 (1969) 1-8.

J. N. Coldstream, "Greeks and Phoenicians in the Aegean". Ed. H.G. Niemeier, Phönizier im Westen. Die Beiträge des Internationalen Symposiums über «Die phönizische Expansion im westlichen Mittelmeerraum» in Köln vom 24. Bis 27. April 1979. Madriger Beiträge Band 8. Mainz am Rhein (1982) 261-275.

A. Coulié, "Les fouilles franco-britanniques au XIX siècle". Eds. A. Coulié - M. Filimonos - Tsopotou, Rhodes. Une ile Greqcue aus Portes de l'Orient. XV $\checkmark$ Siècle Avant J.-C. Paris (2014) $24-35$.

J. C. Courtois, Alasia III. Les Objects des Niveaux Stratifiés d'Enkomi (Fouilles C.F.-A. Schaeffer 1947-1970). Paris 1984.

J. C. Courtois - J. - E. Lagarce, Enkomi et le Bronze Récent à Chypre. Nicosie 1986.

M. Çur, Pedasa Karakol Binası. Yayınlanmamış Yüksek Lisans Tezi, Muğla Sıtkı Koçman Üniversitesi. Muğla 2014.

R. M. Dawkins, The Sanctuary of Artemis Orthia at Sparta. London 1929.

C. Decamps de Mertzenfeld, Invantaire commenté de Ivoires Phéniciens et Apparentés Découvertes dans le Proche-Orient. Paris 1954. 
Deonna 1938

Diler 2009

Diler 2011

Diler 2015

Diler 2016

Diler - Adıgüzel 2015

Diler - Kasar 2016

Ducat 1966

Dunbabin 1957

Fantalkin - Lytle 2016

Fischer 2007

Foster 2016

Freyer-Schauenburg 1966

Friedman 1998

Gardner 1888

von Graeve 2007

Gümüş 2013

Haider 1996

Haider 2001

Haider 2004
W. Deonna, Le Mobilier Délien. Délos XVIII. Paris 1938.

A. Diler, "Tombs and Burials in Damlıboğaz (Hydai) and Pedasa. Preliminary Report in the Light of Surface Investigations and Excavations". Ed. F. Rumscheid, Die Karer und die Anderen. Internationales Kolloquium an der Freien Universität Berlin,13. Bis 15. Oktober 2005. Bonn (2009) $359-376$.

A. Diler, "Pedasa-2008-2009". KST: Kazı Sonuçları Toplantısı 32/4 (2011) 324 341.

A. Diler, "Genel Hatları ile Lykia ve Karia İlişkileri Üzerine Bazı Notlar". Eds. H. İşkan - F. Işık, Kum'dan Kent'e. Patara Kazıları'nın 25. Yılı. Uluslararası Sempozyum Bildirileri, 11 - 13 Kasım 2013, Antalya. Istanbul (2015) 145 - 186.

A. Diler, "Stone Tumuli in Pedasa on the Lelegian Peninsula. Problems of Terminology and Origin". Eds. O. Henry - U. Kelp, Tumulus as Sema. Space, Politics, Culture an Religion in the First Millenium BC. Topoi Vol. 27. Berlin \& Boston (2016) 455- 473.

A. Diler - G. Adıgüzel, "Pedasa Akropolis Giriş Kapısı'nda Kült Çanağı”. Eds. E. Okan - C. Atila, Prof. Dr. Özer Özyiğit'e Armağan. İstanbul (2015) 87- 107.

A. Diler - Ö. Kasar, "Pedasa Buluntusu Pişmiş Toprak Figürinler". Eds. E. Dündar - Ş. Aktaş - M. Koçak - S. Erkoç, Havva İşkan'a Armağan. Lykiarkhissa. İstanbul (2016) $261-280$.

J. Ducat, Les Vases Plaqtiques Rhodiens. Archaïques en terre cuite. Paris 1966.

T. J. Dunbabin, The Greeks and their Eastern Neighbours. Studies in the Relations Between Greece and the Countries of the Near East in the Eighth and Seventh Centuries B.C. London 1957.

A. Fantalkin - E. Lytle, "Alcaeus and Antimenidas: Reassessing the Evidence for Greek Mercenaries in the Neo-Babylonian Army". Klio 98/1 (2016) 90 -117.

E. Fischer, Ägyptische und ägyptisierende Elfenbeine aus Megiddo und Lachish. Inschriftenfunde, Flaschen, Löffel. Münster 2007.

K. P. Foster, "Animal Hybrids, Masks, and Masques in Aegean Ritual". Eds. E. Alram-Stern - F. Blakolmer - S. Deger-Jalkotzy - R. Laffineur - J. Weilhartner, Metaphysis. Ritual, Myth and Symbolism in the Aegean Bronze Age. Proceedings of the $15^{\text {th }}$ International Aegean Conference, Vienna, Insititute for Oriental and European Archaeology, Aegean and Anatolian Department, Austrian Academy of Sciences and Institute of Classical Archaeology, University of Vienna, 22 - 25 April 2014. Aegaeum 39. Leuven \& Liege (2016) 69 - 76.

B. Freyer-Schauenburg, Elfenbeine aus dem samischen Heraion. Figürliches, Gefäbe und Siegel. Hamburg 1966.

Ed. F. Dunn Friedman, Gifts of the Nile. Ancient Egyptian Faience. London 1998.

E. A. Gardner, Naukratis II. London 1888.

V. von Graeve, "Zur Kunstgeschichte früher milesischer Terrakotten". Eds. J. Cobet et al., Frühes Ionien. Eine Bestandsaufnahme. Panionion-Symposion Güzelçamlı 26. September-1. Oktober 1999. Milesische Forschungen Band 5. Mainz am Rhein (2007) 645 - 668.

Ş. Gümüş, Pedasa Leleg Tümülüsleri. Yayınlanmamış Doktora Tezi, Adnan Menderes Üniversitesi. Aydın 2013.

P. W. Haider, "Griechen im Vorderen Orient und Ägypten bis ca. 590 v. Chr". Ed. C. Ulf, Wege zur Genese griechischer Identität. Die Bedeutung der früharchaischen Zeit. Berlin (1996) 59 -115.

P. W. Haider, "Epigraphische Quellen zur Integration von Griechen in die ägyptische Gesellschaft der Saïtenzeit". Eds. U. Höckmann- D. Kreikenbom, Naukratis: die Beziehungen zu Ostgriechenland, Ägypten und Zypern in archaischer Zeit. Akten der Table Ronde in Mainz, 25-27. November 1999. Möhnesee (2001)197-215.

P. W. Haider, "Kontakte zwischen Griechen und Ägyptern und ihre 
Hakimian 2008

Herda 2009a

Herda 2009b

Herda 2013

Hermary 1985

Hermary 2000

Higgins 1954

Hoffman 1997

Hogarth 1908

Höckmann 2012

Höckmann - Vittman 2005

Hölbl 1993

Hölbl 2005

Hölbl 2007

Işık 2004

Jacopi 1932/1933

Jantzen 1972

Jones 1993
Auswirkungen auf die archaisch-griechische Welt". Eds. R. Rollinger- C. Ulf, Griechische Archaik. Interne Entwicklungen- Externe Impulse. Berlin (2004) 447-491.

S. Hakimian, "Byblos". Eds. J. Aruz, K. Benzel, J. M. Evans, Beyond Babylon. Art, Trade, and Diplomacy in the Second Millenium B.C. New Haven \& London (2008) $49-50 ; 52-58$.

A. Herda, "Karerinnen und Karer in Milet: Zu einem spätklassischen Schlüsselchen mit karischem Graffito aus Milet". AA: Archäologischer Anzeiger (2009.2) 51-112.

A. Herda, "Karkiša-Karien und die sogenannte Ionische Migration". Ed. F. Rumscheid, Die Karer und die Anderen. Internationales Kolloquium an der Freien Universität Berlin, 13. Bis 15. Oktober 2005. Bonn (2009) 27-108.

A. Herda, "Greek (and our) Views on the Karians". Eds. A. Mouton - I. Rutherford - I. Yakubovich, Luwian Identities. Culture, Language and Religion Between Anatolia and the Aegean. Leiden \& Boston (2013) 421 - 506.

A. Hermary, "Un noueveau chapiteau hathorique trouvé à Amathonte". $\mathrm{BCH}$ : Bulletin de Correspondance Hellénique 109 (1985) 657-699.

A. Hermary, Les figurines en terre cuite archaïques et Classiques. Les Scupltures en Pierre. Amathonte V. Études Chypriotes 15. Paris 2000.

R. A. Higgins, Cataloque of the Terracottas in the Department of Greek and Roman Antiquities, British Museum Vol. I. Greek: 730-330 BC. London 1954.

G. L. Hoffman, Imports and Immigrants. Near Eastern Contacts with Iron Age Crete. Ann Arbor 1997.

D. G. Hogarth, "Chapter X. Other Ivory and Bone Objects". Ed. D. G. Hogarth, Excavations at Ephesus. The Archaic Artemisia. London (1908) 186-198.

U. Höckmann, "Nokradj/Naukratis aus ägyptischer und griechischer Sicht". Ed. U. Höckmann, Grieschische Keramik des 7. und 6. Jahrhunderts v. Chr. aus Naukratis und anderen Orten in Ägypten. Archäologische Studien zu Naukratis III. Worms (2012) $456-467$.

Höckmann, U. - Vittman, G. "Griechische und karische Söldern in Ägypten in archaischer Zeit (7.-6. Jahrhundert v. Chr)" (Kat. 38-42). Archäologische Zeugnisse". Ed. P. C. Bol Ägypten Griechenland Rom. Abwehr und Berührung. Frankfurt am Mainz (2005) 97-103; 484-490.

G. Hölbl, "Archaische Aegyptiaca aus Ephesos: Vorläufige Beobachtungen zu Neuefunden aus dem Artemision". Eds. G. Dobesch - G. Rehrenböck, Die epigraphische und altertumskundliche Erforschung Kleinasiens: hundert Jahre Kleinasiatische Kommision der Österreichischen Akademie der Wissenschaften. Akten des Symposiums vom 23. Bis 25. Oktober 1990. Wien (1993) 227-253.

G. Hölbl, "Ägyptisches Kulturgut in der griechischen Welt im frühen ersten Jahrtausend vor Christus (10.-6. Jahrhundert v. Chr.)". Ed. C.P. Bol, Ägypten Griechenland Rom. Abwehr und Berührung. Berlin (2005) 114-132; 498-509.

G. Hölbl, "Ionien und Ägypten in archaisher Zeit". Eds. J. Cobet et al., Frühes Ionien. Eine Bestandsaufnahme. Panionion-Symposion Güzelçamlı 26. September-1. Oktober 1999. Milesische Forschungen Band 5. Mainz am Rhein (2007) 447-461.

F. Işık, "Zur anatolischen Athena im Lichte der Athena Ergane von Ilion und der Athena Nikephoros von Pergamon". IstMitt 54 (2004) 507 - 518.

G. Jacopi, Esplorazione Archaeologica di Camiro II. Clara Rhodos 6-7. Rodi 1932/1933.

U. Jantzen, Ägyptische und orientalische Bronzen aus dem Heraion von Samos. Samos Band 8. Bonn 1972.

D. W. Jones, "Phoenician Unguent Factories in Dark Age Greece: Social Approaches to Evaluating the Archaeological Evidence". Oxford Journal of Archaeology 12 (1993) 293-303. 
Kammerzell 2001

Kantor 1958

Kaplan 2002

Karageorghis 1973

Kilian - Dirlmeier 1985

Kilian - Dirlmeier 2000

Kourayos - Burns 2017

Kourou 2003

Kourou 2008

Kourou 2015

Kunze 1935-1936

Kyrieleis 2009

Lagarce- Leclant 1976

Laumonier 1958

Lubos 2009

Luraghi 2006

Lurker 1994
F. Kammerzell, “Die Geschichte der karischen Minderheit in Ägypten”. Eds. U. Höckmann- D. Kreikenbom, Naukratis: die Beziehungen zu Ostgriechenland, Ägypten und Zypern in archaischer Zeit. Akten der Table Ronde in Mainz, 2527. November 1999. Möhnesee (2001) 233-255.

H. J. Kantor, "VII. The Ivories from Floor 6 of Sounding IX". Ed. C. W. MacEwan, Soundings at Tell Fakhariyah. Chicago (1958) 57-68.

P. Kaplan, "The Social Status of the Mercenary in Archaic Greece". Eds. V. B. Gorman - E. W. Robinson, Oikistes. Studies in Constitutions, Colonies, and Military Power in the Archaic World. Offered in Honor of A. J. Graham. Leiden \& Boston \& Köln (2002) $229-243$.

V. Karageaorghis, Excavations in the Necropolis of Salamis III. Salamis Vol. 5. Nicosia 1973.

I. Kilian- Dirlmeier, "Fremde Weihungen in griechischen Heiligtümern vom 8. bis zum Beginn des 7. Jahrhunderts v. Chr.". JbRGZM: Jahrbuch des RömischGermanischen Zentralmuseums Mainz 32 (1985) 215-254.

I. Kilian- Dirlmeier, "Orientalia in Griechenland vom 13.-9. Jahrhundert v. Chr.". Ed. C. Işık, Studien zur Religion und Kultur Kleinasiens und des ägäischen Bereiches. Festschrift für Baki Ögün zum 75. Geburstag. Asia Minor Studien Band 39. Bonn (2000) 151-163.

Y. Kourayos- B. Burns, "A Deposit of Small Finds from the Sanctuary of Apollo on the Island Despotiko". Ed. M. Ainian, Les Sanctuaries Archaïques des Cyclades. Recherches Récentes. Rennes (2017) 327-344.

N. Kourou, "Rhodes: the Phoenician Issue Revisited. Phoenicians at Vroulia?". Eds. N. Chr. Stampolidis- V. Karageorghis, Sea Routes. Interconnections in the Mediterranean. $16^{\text {th }}-6^{\text {th }}$ c. BC. Proceedings of the International Symposium held at Rethymnon, Crete in September $29^{\text {th }}$ - October $2^{\text {nd }}$ 2002. Athens (2003) 249-262.

N. Kourou, "The Evidence from the Aegean". Ed. C. Sagona, Beyond the Homeland: Markers in Phoenician Chronology. Ancient Near Eastern Studies Supplement 28. Leuven \& Paris \& Dudley, MA. (2008) 305-3564.

N. Kourou, "Literacy, networks and social synamics in Archaic Rhodes". Eds. S. Nawracala - R. Nawracala, Polymatheia. Festschrift für Hartmut Matthäus anläBlich seines 65. Geburtstages. Aachen (2015) 245-263.

E. Kunze, "Orientalische Schnitzereien aus Kreta". AM: Athenische Mitteilungen 60-61 (1935-1936) 218-233.

H. Kyrieleis, "Intercultural Commerce and Diplomacy: Near Eastern, Egyptian and Cypriote Artefacts from the Heraion of Samos". Eds. V. Karageorghis - O. Kouka, Cyprus and the East Aegean. Intercultural Contacts from 3000 to 500 BC. An International Archaeological Symposium held at Pythagoreion, Samos, October $17^{\text {th }}-18^{\text {th }} 2008$. Nicosia (2009) $139-143$.

E. Lagarce- J. Leclant, "Vase plastique en faïence Kit. 147: Une fiole pour eau de jouvence". Eds. G. Clerc, V. Karageorghis, E. Lagarce, J. Leclant, Fouilles de Kition. II. Objects Égyptiens et Égyptisants: Scarabées, Amulettes et Figurines en Pâte de verre et en Faïence, Vase Plastique en Faïence. Sites I et II, 19591975. Nicosia (1976) 183-290.

A. Laumonier, Les Cultes Indigènes en Carie. Paris 1958.

M. Lubos, "Weihungen griechischer Söldern in Didyma". Eds. R. Einicke et al., Zurück zum Gegenstand. Festschrift für Andreas E. Furtwängler. Langenweißbach (2009) $405-414$.

N. Luraghi, "Traders, Pirates, Warriors: the Proto-history of Greek Mercenary Soldiers in the Eastern Mediterranean". Phoenix: The Journal of the Classical Association of Canada 60 (2006) 21-47.

M. Lurker, An Illustrated Dictionary of The Gods and Symbols of Ancient Egypt. London 1994. 
Loud 1939

Llyod 1975

Maiuri 1928

Margueron 2008

Martinelli 2000

Masson - Yoyette 1988

Matthäus 2009

Möller 2000

Muhly 2006

Murray 1980

Muss 2008

Niemeier 2001

Niemeier 2016

Norton 1908

Özer 2009

Özer 2012

Özer 2015a

Özer 2015b

Özer 2016

Özer 2017a

Özer 2017b

Özer 2018a
G. Loud, The Megiddo Ivories. Chicago \& Illinois 1939.

A. B. Llyod, Herodotus Book II. Introduction. Leiden 1975.

A. Maiuri, "Jalisos E L'Agro Jalisio". Eds. A. Maiuri - G. Jacopi, Rapporto Generale Sul Servizio Archeologico a Rodi e nelle Isole Dipendenti dall'anno 1912 all'anno 1927. Clara Rhodos I. Rodi (1928) 76-78.

J. C. Margueron, "Ugarit: Gateway to the Mediterranean". Eds. J. Aruz, K. Benzel, J. M. Evans, Beyond Babylon. Art, Trade, and Diplomacy in the Second Millenium B.C. New Haven \& London (2008) 236 - 250.

M. Martinelli, "La Stipe di lalysos: Avori Orientali e Greci". Eds. G. Chessari - A. di Vita, Un Ponte fra L'Italia e La Grecia. Atti del Simposio in onore di Antonini di Vita. Ragusa, 13-15 febbraio 1998. Padova (2000) 105-118.

O. Masson - J. Yoyette, "Une Inscription Ionienne Mentionant Psammétiqueler". EA: Epigraphica Anatolica 11(1988) 171 - 180.

H. Matthäus, "Near Eastern Ivories in the Aegean During the Early First Millenium B.C. and their Impact on Local Greek Art". Eds. S. M. Cecchini - S. Mazzoni - E. Scigliuzzo, Syrian and Phoenician Ivories of the Early First Millenium BCE: Chronology, Regional Styles and Iconographic Repertories, Patterns of Inter-regional Distribution. Acts of the International Workshop Pisa, December $9^{\text {th }}-11^{\text {th }}$ 2004. Pisa (2009) 319-333.

A. Möller, Naukratis. Trade in the Archaic Greece. Oxford 2000.

J. Muhly, "Travelling Craftsmen: Love 'em or Leave 'em". Eds. R. Laffineur- E. Greco, Emporia. Aegeans in the Central and Eastern Mediterranean. Proceedings of the $10^{\text {th }}$ International Aegean Conference Athens, Italian School of Archaeology, 14-18 April 2004. Aegaeum 25. Liège (2006) 685-690. O. Murray, Early Greece. New Jersey 1980.

U. Muss, "Efes Artemisionu'nda Bulunan Fildişi ve Kemik Eserler". Ed. W. Seipel, Efes Artemisionu. Bir Tanrıça'nın Kutsal Mekanı. Viyana Kunsthistorisches Museum Sergi Kataloğu. Viyana (2008) 215-250.

W.-D. Niemeier, "Archaic Greeks in the Orient: Textual and Archaeological Evidence". BASOR: Bulletin of the American Schools of Oriental Research 322 (2001) 11-32.

W.-D. Niemeier, "Greek Sanctuaries and the Orient". Eds. J. Aruz - M. Seymour, Assyria to Iberia. Art and Culture in the Iron Age. New York (2016) 234-250.

R. Norton, "Engraved Stone, Gems and Ivories". Ed. C. Waldstein, The Argive Heraeum Vol. II. Terra-cotta Figurines, Terra-cotta Reliefs, Vases and Vase Fragments, Bronzes, Engraved Stones, Gems, and Ivories, Coins, Egyptian, or Greco-Egyptian, Objects. Boston \& New York (1905) 343-354.

B. Özer, "Kutsal Alan Sektörü Çalışmaları". A. Diler et al., "Pedasa, 2007". KST: Kazı Sonuçları Toplantısı 30/3 (2009) 273- 274.

B. Özer, "Kutsal Alan: Antik Yol Açma 1 Sondajı". A. Diler et al., "Pedasa, 2010". KST: Kazı Sonuçları Toplantısı 33/4 (2012) 172-175.

B. Özer, "Kutsal Alan Batı Teras Sondajı". A. Diler et al., "Pedasa 2013". KST: Kazı Sonuçları Toplantısı 36/3 (2015) 344-347.

B. Özer, "Kıуı Karya Arkaik Seramiği: Yerel Formlar, Kültürel Sınırlar". Eds. E. Okan - C. Atila, Prof. Dr. Ömer Özyiğit'e Armağan (İstanbul 2015) 331-347.

B. Özer, "Kutsal Alan Orta Teras Sondajı". A. Diler et al., "Pedasa 2014". KST: Kazı Sonuçları Toplantısı 37/3 (2016) 562-565.

B. Özer, "Pedasa Athena Kutsal Alanı Arkaik Dönem Kıbrıs Mortarları ve Bölgeler Arası Ticari ilişkilerdeki Rolü”. Adalya 20 (2017) 41-67.

B. Özer, "Kıyı Karia Arkaik Seramiği: Karia Kaseleri ve Denizaşırı Dağıııları". Arkeoloji ve Sanat 156 (Eylül-Aralık 2017) 61-76.

B. Özer, "Pedasa'dan Erken Demir Çağ Başlarına Ait Mezar Platformları ve Urne Pithoslar". TÜBA-AR: Türkiye Bilimler Akademisi Arkeoloji Dergisi 22 (2018) $35-55$. 
Özer 2018b

Özer - Özer 2017

Özer-Türkoğlu 2009

Payne 1940

Paton-Myres 1896

Pendlebury 1930

Petrie 1886

Sakellarakis 1993

de Salvia 1991

Schofield 1992

Schaeffer 1954

Shaw 1989

Smith 1908

Stampolidis - Kotsonas 2006

Strøm 1992

Stubbings 1962

Şahin 1987

Tufnell 1940

Tuna 2012

Varvarinou-Vai 2017

Verčík 2017
B. Özer, "Kıуı Karia Arkaik Dönem Seramiği: Miletos Tipinde Ticari Amphoralar ve Bölgesel Amphora Üretimi ve Dağılımı Üzerine Bazı Sorular ve Ön Görüşler". Phaselis IV (2018) 89 -107. http://dx.doi.org/10.18367/Pha.18007

B. Özer - Ö. Şimşek Özer, "Asarlık Paton Tomb O: Some Observations on Funerary Practices of Lelegian Peninsula in $12^{\text {th }}$ Century BC and the Arrival of the Newcommers". Colloquium Anatolicum 16 (2017) $139-162$

B. Özer - S. Türkoğlu, "Karakol Binası". A. Diler et al., "Pedasa, 2007". KST: Kazı Sonuçları Toplantısı 30/3 (2009) 270 -272.

Ed. H. Payne, Perachora I. The Sanctuaries of Hera Akraia and Limenia. Achitecture, Bronzes and Terrecottas. Oxford 1940.

W.R. Paton- J. L. Myres, "Karian Sites and Inscriptions". JHS: The Journal of Hellenic Studies 16 (1896) 188-271.

J. D. S. Pendlebury, Aegyptiaca. A Cataloque of Egyptian Objects in the Aegean Area. Cambridge 1930.

W. M. F. Petrie, Naukratis I. London 1886.

J. A. Sakellarakis, "Ivory Trade in the Aegean in the $8^{\text {th }}$ Century B.C.E.". Eds. A. Brian - J. Aviram, Biblical Archaeology Today, 1990: Proceedings of the Second International Congress on Biblical Archaeology, Jerusalem, June-July 1990. Jerusalem (1993) 345-366.

F. de Salvia, "Stages and Aspect of the Egyptian Religious and Magic Influences on Archaic Greece". Ed. S. Schoske, Akten des vierten internationalen Ägyptologen Kongresses München 1985, Band 4. Geschichte, Verwaltungs und Wirstchaftsgeschicte, Rechtsgeschichte, Nachbarnkulturen. Hamburg (1991) 335-343.

L. Schofield, "The Influence of Eastern Religions on the Iconography of Ivory and Bone Objects in the Kameiros Well". Ed. J. L. Fitton, Ivory in Greece and the Eastern Mediterranean from the Bronze Age to the Hellenistic Period. British Museum Occasional Paper, 85. London (1992) 173-184.

C. F.- A. Schaeffer, "Les fouilles de Ras Shamra - Ugarit. Quinzième, seizième et dix-septième campagnes (1951, 1952 et 1953). Rapport Sommaire". Syria 31 (1954) $14-67$

J. Shaw, "The Phoenicians in Southern Crete". AJA: American Journal of Archaeology 93 (1989) 165-183.

C. Smith, "Chapter IX. The Ivory Statuettes". Ed. D.G. Hogarth, Excavations at Ephesus. The Archaic Artemisia. London (1908) 155-185.

N. Chr. Stampolidis - A. Kotsonas, "Phoenicians in Crete". Eds. S. DegerJalkotzy - I. Lemos, Ancient Greece. From the Mycenaean Palaces to the Age of Homer. Edinburg (2006) 337-360.

I. Strøm, "Evidence from the Sanctuaries". Eds. G. Kopcke- I. Tokumaru, Greece Between East and West, 10th-8th. Centuries BC. Papers of the Meeting at the Institute of Fine Arts, New York University, March 15-16th, 1990. Mainz (1992) 46-60.

J. M. Stubbings, "Part Two. Ivories". Ed. T. J. Dunbabin, Perachora II. Pottery, Ivories, Scarabs, and Other Objects from the Votive Deposit of Hera Limenia. Oxford (1962) 403-451.

Ç. Şahin, "Zwei Inschriften aus dem südwestlichen Kleinasien". EA: Epigraphica Anatolica 10 (1987) 1-2.

O. Tufnell, Lachish (Tell Ed Duweir) II. The Fosse Tempel. London 1940.

N. Tuna, Knidos Teritoryumu'nda Arkeolojik Araştırmalar. Ankara 2012.

D. Varvarinou-Vai, "Small Finds from the Sanctuary of Kythnos: The Bone and Ivory Jewellery". Ed. M. Ainian, Les Sanctuaries Archaïques des Cyclades. Recherches Récentes. Rennes (2017) 193-200.

M. Verčík, "The lonians at War? Die Waffenweihungen in den ionischen Heiligtümern und das Apollon - Heiligtum von Didyma". Studia Hercynia 
Vermeule - Wolsky 1977

Vittmann 2003

Ward 1969

Webb 1978

Webb 2016

Williams-Villing 2006

Winlock 1934
$X X I / 2(2017) 7-26$.

E. T. Vermeule- F.Z. Wolsky, "The Bone and Ivory of Toumba tou Skourou". RDAC: Report of the Department of Antiquities Cyprus (1977) 80-96.

G. Vittmann, Ägypten und die Fremden im ersten vorchristlichen Jahrtausend. Mainz am Rhein 2003.

W. A. Ward, "La déesse nourricière d'Ugarit". Syria 46 (1969) 225 - 239.

V. Webb, Archaic Greek Faience, Miniature Scent Bottles and Related Objects from East Greece, 650-500 B.C. Warminster 1978.

V. Webb, Faience Material from the Samos Heraion Excavations. Samos Band 13. Berlin 2016.

D. Williams- A. Villing, "Carian Mercenaries at Naukratis?". Eds. A. Villing - U. Schlotzhauer, Naukratis: Greek Diversity in Egypt. Studies on East Greek Pottery and Exchange in the Eastern Mediterranean. London (2006) 47-48. H. E. Winlock, The Treasure of El Lāhūn. New York 1934. 